\title{
Site-Directed Mutations at D1-His198 and D2-His197 of Photosystem II in Synechocystis PCC 6803: Sites of Primary Charge Separation and Cation and Triplet Stabilization ${ }^{\dagger}$
}

\author{
Bruce A. Diner, ${ }^{*}, \stackrel{\ddagger}{ }$ Eberhard Schlodder,${ }^{\S}$ Peter J. Nixon," William J. Coleman, ${ }^{\perp}$ Fabrice Rappaport, ${ }^{\#}$
} Jérôme Lavergne, ${ }^{\times}$Wim F. J. Vermaas, ${ }^{+}$and Dexter A. Chisholm ${ }^{*}$

CR \& D, Experimental Station, E. I. du Pont de Nemours \& Co., Wilmington, Delaware 19880-0173, Technische Universität Berlin, Strasse des 17. Juni 135, 10623 Berlin, Germany, Department of Biochemistry, Imperial College, London, SW7 2AY, U.K., Inc., 10225 Barnes Canyon Road, A110, San Diego, California 92121, IBPC, 13 rue Pierre et Marie Curie, 75005 Paris, France, CEA-Cadarache, DEVM, Laboratoire de Bioénergétique Cellulaire, 13108 Saint Paul-lez-Durance, France, and Department of Plant Biology, Arizona State University, Tempe, Arizona 85287-1601

Received January 18, 2001; Revised Manuscript Received May 31, 2001

ABSTRACT: Site-directed mutations were introduced to replace D1-His198 and D2-His197 of the D1 and D2 polypeptides, respectively, of the photosystem II (PSII) reaction center of Synechocystis PCC 6803. These residues coordinate chlorophylls $\mathrm{P}_{\mathrm{A}}$ and $\mathrm{P}_{\mathrm{B}}$ which are homologous to the special pair Bchlorophylls of the bacterial reaction centers that are coordinated respectively by histidines L-173 and M-200 (202). $\mathrm{P}_{\mathrm{A}}$ and $\mathrm{P}_{\mathrm{B}}$ together serve as the primary electron donor, $\mathrm{P}$, in purple bacterial reaction centers. In PS II, the site-directed mutations at D1 His198 affect the $\mathrm{P}^{+}-\mathrm{P}$-absorbance difference spectrum. The bleaching maximum in the Soret region (in WT at $433 \mathrm{~nm}$ ) is blue-shifted by as much as $3 \mathrm{~nm}$. In the D1 His198Gln mutant, a similar displacement to the blue is observed for the bleaching maximum in the $\mathrm{Q}_{y}$ region $(672.5$ $\mathrm{nm}$ in WT at $80 \mathrm{~K}$ ), whereas features attributed to a band shift centered at $681 \mathrm{~nm}$ are not altered. In the $\mathrm{Y}_{\mathrm{Z}^{\bullet}}-\mathrm{Y}_{\mathrm{Z}}$-difference spectrum, the band shift of a reaction center chlorophyll centered in WT at 433-434 $\mathrm{nm}$ is shifted by $2-3 \mathrm{~nm}$ to the blue in the D1-His198Gln mutant. The D1-His198Gln mutation has little effect on the optical difference spectrum, ${ }^{3} \mathrm{P}-{ }^{1} \mathrm{P}$, of the reaction center triplet formed by $\mathrm{P}^{+} \mathrm{Pheo}^{-}$charge recombination (bleaching at $681-684 \mathrm{~nm}$ ), measured at 5-80 K, but becomes visible as a pronounced shoulder at $669 \mathrm{~nm}$ at temperatures $\geq 150 \mathrm{~K}$. Measurements of the kinetics of oxidized donor $-\mathrm{Q}_{\mathrm{A}}{ }^{-}$charge recombination and of the reduction of $\mathrm{P}^{+}$by redox active tyrosine, $\mathrm{Y}_{\mathrm{Z}}$, indicate that the reduction potential of the redox couple $\mathrm{P}^{+} / \mathrm{P}$ can be appreciably modulated both positively and negatively by ligand replacement at D1-198 but somewhat less so at D2-197. On the basis of these observations and others in the literature, we propose that the monomeric accessory chlorophyll, $\mathrm{B}_{\mathrm{A}}$, is a long-wavelength trap located at $684 \mathrm{~nm}$ at $5 \mathrm{~K} . \mathrm{B}_{\mathrm{A}} *$ initiates primary charge separation at low temperature, a function that is increasingly shared with $\mathrm{P}_{\mathrm{A}} *$ in an activated process as the temperature rises. Charge separation from $\mathrm{B}_{\mathrm{A}}{ }^{*}$ would be potentially very fast and form $\mathrm{P}_{\mathrm{A}}{ }^{+} \mathrm{B}_{\mathrm{A}}{ }^{-}$and/or $\mathrm{B}_{\mathrm{A}}{ }^{+} \mathrm{Pheo}^{-}$as observed in bacterial reaction centers upon direct excitation of $\mathrm{B}_{\mathrm{A}}$ (van Brederode, M. E., et al. (1999) Proc. Natl. Acad Sci. 96, 2054-2059). The cation, generated upon primary charge separation in PSII, is stabilized at all temperatures primarily on $\mathrm{P}_{\mathrm{A}}$, the absorbance spectrum of which is displaced to the blue by the mutations. In WT, the cation is proposed to be shared to a minor extent $(\sim 20 \%)$ with $\mathrm{P}_{\mathrm{B}}$, the contribution of which can be modulated up or down by mutation. The band shift at $681 \mathrm{~nm}$, observed in the $\mathrm{P}^{+}-\mathrm{P}$ difference spectrum, is attributed to an electrochromic effect of $\mathrm{P}_{\mathrm{A}}^{+}$on neighboring $\mathrm{B}_{\mathrm{A}}$. Because of its low-energy singlet and therefore triplet state, the reaction center triplet state is stabilized on $\mathrm{B}_{\mathrm{A}}$ at $\leq 80 \mathrm{~K}$ but can be shared with $\mathrm{P}_{\mathrm{A}}$ at $>80 \mathrm{~K}$ in a thermally activated process.

\section{INTRODUCTION}

The primary electron donor of the reaction centers of the purple non-sulfur photosynthetic bacteria is a pair of exci-

\footnotetext{
Support of the NRICGP/USDA (97-35306-4882) to B.A.D. and W.J.C., of the Deutsche Forschungsgemeinschaft (Sfb 498, TP A1) to E.S., of the Royal Society and BBSRC to P.J.N., of the CNRS to F.R. and of the CNRS and the CEA to J.L., and of the NSF (MCB97-28400) to W.F.J.V. is gratefully acknowledged. This article is contribution No. 8050 of the Central Research and Development Department of E. I. du Pont de Nemours \& Co. We dedicate this paper to the memory of Dr. Gerald T. Babcock.

$\doteqdot$ E. I. du Pont de Nemours \& Co.

$\S$ Technische Universität Berlin.

"Imperial College.

${ }^{\perp}$ Kairos Scientific.

\# IBPC.

$\times$ Laboratoire de Bioénergétique Cellulaire.

+ Arizona State University.
}

tonically coupled bacteriochlorophyll (BChl) $)^{1}$ molecules ( 1 , 2), $\mathrm{P}_{\mathrm{A}}$ and $\mathrm{P}_{\mathrm{B}}$, coordinated by L-His173 and M-His200 (202), respectively $(3-5)$. Upon photooxidation of the primary donor, the oxidizing equivalent is either shared between or localized on one member of the special pair (6). There are substantial amino acid sequence homologies between the bacterial reaction centers and photosystem II (PSII) (7-10). The histidines that coordinate $\mathrm{P}_{\mathrm{A}}$ and $\mathrm{P}_{\mathrm{B}}$ of the bacterial reaction centers are conserved in PSII at D1-His198 and D2His197, respectively, and are prime candidates for the coordination of the primary donor, P. Despite this conservation, there are a number of key differences between the two types of centers: (1) The oxidized donor $\mathrm{P}^{+}$of PSII has a much more positive reduction potential than its bacterial homologue $(11,12)$. (2) The exciton coupling attributed to 
$\mathrm{P}\left(\sim 140 \mathrm{~cm}^{-1} ; 13-16\right)$ is far weaker than that associated with the bacterial primary donor $\left(500-1000 \mathrm{~cm}^{-1} ; 1\right)$, most likely because of the greater separation $(10 \AA$ center to center) of $\mathrm{P}_{\mathrm{A}}$ and $\mathrm{P}_{\mathrm{B}}(17,18)$. (3) The $\mathrm{P}$ triplet, formed through charge recombination, at liquid helium temperature, between the primary donor-acceptor pair, is localized on a monomeric chlorophyll (19-23) with an orientation more like that of the bacterial reaction center monomeric accessory Bchlorophylls, $\mathrm{B}_{\mathrm{A}}$ or $\mathrm{B}_{\mathrm{B}}(15,24)$, while in bacterial reaction centers the triplet orientation is consistent with its localization on one or both of $\mathrm{P}_{\mathrm{A}}$ and $\mathrm{P}_{\mathrm{B}}(25,26)$. It has been suggested that the triplet and possibly the cation radical itself may be localized either on the PSII homologue of $\mathrm{B}_{\mathrm{A}}$ or $\mathrm{B}_{\mathrm{B}}(24,27)$ or that $\mathrm{P}_{\mathrm{A}}$ or $\mathrm{P}_{\mathrm{B}}$ or both in PSII have an orientation more like that of an accessory $\mathrm{BChl}$ than that of the special pair BChls of the bacterial reaction centers $(24,28,29)$. There has been considerable debate as to whether the cation and the triplet are localized on the same chlorophyll $(28,30)$ or whether there might be migration of either the triplet (27, $31)$ or of the cation radical $(32,33)$. Rutherford and collaborators $(32,34)$, on the basis of the orientation of ${ }^{3} \mathrm{P}$ in PSII, and Van Grondelle and collaborators $(33,35)$, on the basis of observations of charge separation following direct photoexcitation of $\mathrm{B}_{\mathrm{A}}$ in bacterial reaction centers, have in fact suggested alternative mechanisms for charge separation in PSII originating from $\mathrm{B}_{\mathrm{A}}{ }^{*}$. The respective localization and mechanism of formation of the $\mathrm{P}^{+}$cation radical and of ${ }^{3} \mathrm{P}$ therefore remain key questions regarding PSII reaction center function.

One of the major difficulties in identifying the processes leading to and the components participating in charge separation in PSII is the close similarity in the absorbance spectra of the chlorophylls that comprise the reaction center and the core antenna. One approach to dissecting these processes is by tagging the component chlorophylls by introducing spectroscopic markers and by modifying their redox function through the introduction of site-directed mutations.

Site-directed replacement of either of the His- $\mathrm{Mg}^{2+}$ ligands (L-His173 and M-His202) of P870 by Leu or Phe $(36,37)$ or Glu $(38)$ leads to the replacement of the respective special pair BChl by a bacteriopheophytin (BPheo) leading to the formation of a heterodimeric $\mathrm{BChl}-\mathrm{BPheo}$ special pair. While such replacement appears to result from a loss of the $\mathrm{Mg}$ coordinate covalent bond, substitution for the coordinating His of Gly $(38,39)$ does not lead to replacement of BChl. Despite the absence of a coordinating residue in

\footnotetext{
${ }^{1}$ Abbreviations: $\mathrm{B}_{\mathrm{A}}$, monomeric accessory $\mathrm{Chl}$ on the active $\mathrm{D} 1$ branch of the reaction center; $\mathrm{B}_{\mathrm{B}}$, monomeric accessory $\mathrm{Chl}$ on the inactive D2 branch of the reaction center; $\mathrm{BChl}$ or Bchlorophyll, bacteriochlorophyll; BPheo, bacteriopheophytin; Chl, chlorophyll; D1, the D1 polypeptide of the PSII reaction center; D2, the D2 polypeptide of the PSII reaction center; DCMU, diuron, 3-(3,4-dichlorophenyl)1,1-dimethylurea; EPR, electron paramagnetic resonance; FTIR, Fourier transform infrared spectroscopy; HEPES, $N$-(2-hydroxyethyl)piperazine$N^{\prime}$-(2-ethanesulfonic acid); HPLC, high-performance liquid chromatography; MES, 2-( $N$-morpholino)ethanesulfonic acid; $\mathrm{P}$, the primary electron donor of PSII; ${ }^{3} \mathrm{P}$, the triplet state of the primary electron donor of PSII; $\mathrm{P}_{\mathrm{A}}$, the chlorophyll coordinated by D1-His198; $\mathrm{P}_{\mathrm{B}}$, the chlorophyll coordinated by D2-His197; Ph or Pheo, pheophytin; PSII, photosystem II; $\mathrm{Q}_{\mathrm{A}}$, the primary quinone electron acceptor of PSII; $\mathrm{Q}_{\mathrm{B}}$, the secondary quinone electron acceptor of PSII; WT, wild-type Synechocystis 6803; $\mathrm{Y}_{\mathrm{D}}, \mathrm{D} 2-\mathrm{Tyr} 160$, the redox active tyrosine of PSII on the D2 polypeptide; $Y_{Z}, D 1-T y r 161$, the redox active tyrosine of PSII on the D1 polypeptide.
}

the case of the glycine mutant, it is likely that a water molecule has taken its place (39). The consequences of the Gly, Asn, and Ser substitutions $(38,39)$ are, however, rather subtle with only very minor changes observed in the absorbance and Stark spectra and electronic spin density distribution and only a small increase $(\leq 21 \mathrm{mV})$ in the reduction potential of the primary donor. Small changes in the Resonance Raman spectra of the bacterial L-His173Gly and M-His202Gly (39) hint at minor changes in the $\mathrm{Mg}^{2+}$ coordination environment. A considerable number of sitedirected replacements have also been introduced in Chlamydomonas reinhardtii to replace A-His676 and B-His656, the WT residues that coordinate the special pair chlorophylls that constitute the primary electron donor, P700, of PSI. Many of these allow in vivo accumulation of PSI and produce substantial increases in the reduction potential of the redox couple $\mathrm{P} 700^{+} / \mathrm{P} 700$ and a displacement to the blue of the $77 \mathrm{~K}$ oxidized-minus-reduced difference spectrum of P700 (40, 41).

We describe here the construction in PSII of a collection of mutations with and without metal coordinating residues at the positions of the homologous histidines, D1-His198 and D2-His197 $(8-10,18,42,43)$. Our intent was to introduce perturbations affecting individual chlorophyll molecules and to examine the consequences these had on the spectroscopic properties of the primary electron donor, $\mathrm{P}$, and the reaction center triplet, ${ }^{3} \mathrm{P}$, as well as on the redox properties of the primary donor. We show here, using the cyanobacterium Synechocystis 6803 that replacement of D1-His198 and of D2-His197 with $\mathrm{Mg}^{2+}$-coordinating residues and with small residues bearing alkyl side chains conserves reaction center Chl but produces changes that are more marked than those observed in the bacterial reaction centers. The changes observed include shifts in the difference spectra $\mathrm{P}^{+}-\mathrm{P}$ and

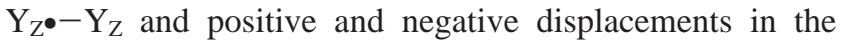
reduction potential of $\mathrm{P}^{+} / \mathrm{P}$. The mutations produce practically no differences in either the EPR or the difference optical spectra associated with the reaction center triplet, ${ }^{3} \mathrm{P}-{ }^{1} \mathrm{P}$, at $\leq 80 \mathrm{~K}$. The observations presented allow us to place the lowest electronic singlet transition of $\mathrm{P}_{\mathrm{A}}\left(\lambda_{\max }=672.5 \mathrm{~nm}\right)$ at higher energy than that of $\mathrm{B}_{\mathrm{A}}\left(\lambda_{\max }=684 \mathrm{~nm}\right)$ which means that at $\leq 80 \mathrm{~K}$ primary charge separation must be occurring exclusively from $\mathrm{B}_{\mathrm{A}}{ }^{*}$. The $\mathrm{P}^{+}$cation is at all temperatures, however, subsequently stabilized primarily on the $\mathrm{P}_{\mathrm{A}}$ chlorophyll, coordinated by D1-His198.

\section{MATERIALS AND METHODS}

Mutant Construction. With the exception of the glycine substitution, mutations at codon 198 of the $p s b \mathrm{~A} 3$ gene, encoding the D1 subunit, were introduced into the TD41 psbA triple deletion strain of Synechocystis PCC6803 as described in Nixon et al. (44). The mutant D1-His198Gly was constructed using the Chameleon Mutagenesis Kit from Stratagene. A mutagenesis plasmid (designated $\mathrm{pC} 1$ ) was first constructed by subcloning the $1.7 \mathrm{kB} B s r G$ I-Sph I fragment from plasmid pTC3 (44), which contains most of the WT $p s b \mathrm{~A} 3$ gene, into the Litmus 38 vector from New England Biolabs. An antisense mutagenic primer was used which replaces the His-198 CAC codon with a glycine GGT codon. The Stratagene Sca I-Mlu I selection primer was also employed to enrich for mutagenized plasmids. Mutagenesis was carried out according to the manufacturer's instructions. 
Introducing the CAC $\rightarrow$ GGT mutation simultaneously removes an Afl III restriction site, and this change was subsequently used to screen for possible mutants. A putative mutant identified and sequenced in the $\mathrm{pC} 1$ plasmid was then cloned back into pTC3 for transformation into Synechocystis PCC6803 deletion strain TD41 (44). Mutations at codon 197 of the psbD1 gene encoding the D2 subunit were introduced as previously described $(45,46)$.

Characterization of Core Complexes and Cells. Nonoxygen-evolving PSI II core complexes were isolated from the mutants according to the methods previously described $(47,48)$. Unless otherwise indicated, all optical absorption and fluorescence measurements were performed at room temperature as previously described (49-51) using a flash detection spectrophotometer, based upon an original design by Joliot et al. (52). A saturating xenon flash (1 $\mu$ s width at half-height) was used as the actinic source where whole cells were used. A laser flash $(0.6$ or $1 \mu$ s total width, using a Cynosure SLL-250 or LDL-3 dye laser, respectively) containing either Rhodamine 6G, Sulforhodamine 640, or Oxazine 720 was the actinic source where PSII core complexes were used. The functional PSII reaction center concentration on a per cell basis was determined relative to the wild type, as previously described (53), by measuring the variable fluorescence yield of chlorophyll during a sequence of 20 saturating light flashes $(18 \mathrm{~Hz})$. The measurement was performed in the presence of $20 \mu \mathrm{M}$ DCMU and $20 \mathrm{mM} \mathrm{NH}_{2} \mathrm{OH}$ in cells previously treated with $0.3 \mathrm{mM} p$-benzoquinone and $0.3 \mathrm{mM}$ potassium ferricyanide. The cells were suspended at a concentration equivalent to an $\mathrm{OD}_{730 \mathrm{~nm}}=0.9$.

Low-temperature optical measurements of $\mathrm{P}^{+}-\mathrm{P}$ and ${ }^{3} \mathrm{P}-$ ${ }^{1} \mathrm{P}$ were performed on PSII core complexes as previously described (54). Sub-microsecond, flash-induced absorbance changes were measured at room temperature in an instrument described by Béal et al. (55).

EPR measurements were performed using PS II core complexes (at a final concentration of $\sim 1 \mathrm{mg} \mathrm{Chl} \mathrm{mL}{ }^{-1}$ ) suspended in buffer containing $50 \%$ glycerol (v/v), $40 \mathrm{mM}$ MOPS (pH 7.0), $20 \mathrm{mM} \mathrm{CaCl}_{2}, 5 \mathrm{mM} \mathrm{MgCl}, 20 \mathrm{mM}$ $\mathrm{MgSO}_{4}, 0.8 \mathrm{mM}$ EDTA, and $0.03 \%$ dodecyl maltoside. The samples were chemically reduced with $20 \mathrm{mM}$ sodium dithionite and $0.1 \mathrm{mM}$ benzyl viologen (56) and purged with argon before freezing in darkness in Wilmad 707-SQ quartz EPR tubes. The tubes were stored frozen in liquid nitrogen until use. The spin-polarized triplet was generated by continuous illumination at $4 \mathrm{~K}$ in the EPR cavity. Illumination was provided by an Ealing halogen light source passed through a 2-cm water filter, a Melles-Griot heat-absorbing filter, and a 40-cm Lucite light guide. Spectra were obtained on a Bruker ER200D spectrometer fitted with an Oxford cryostat. The spectra shown are light-minus-dark subtractions.

The chlorophyll/pheophytin in PSII core complexes was determined as previously described (48). The pigments were extracted with $90 \%$ acetone and then separated by reverse phase on a Zorbax-ODS HPLC column $(4.6 \mathrm{~mm} \times 15 \mathrm{~cm}$, Rockland Technologies) according to Eskins et al. (57).

The concentration of DCMU binding sites was estimated according to Vermaas et al. (58) using whole cells at a concentration of $25 \mu \mathrm{g}$ of $\mathrm{Chl} / \mathrm{mL}$ and incubated at various

\begin{tabular}{lclc}
\hline \multicolumn{1}{c}{ Table 1: Photoautotrophy, Oxygen } & Rates, and Center Content \\
\hline mutant & $\begin{array}{c}\text { photoautotrophic } \\
\text { growth }\end{array}$ & $\begin{array}{c}\text { \% oxygen } \\
\text { evolution rate }\end{array}$ & $\begin{array}{c}\text { \% of WT PSII } \\
\text { reacn centers }\end{array}$ \\
\hline WT & + & 100 & 100 \\
D1-His198Gln & + & 100 & $80-100$ \\
D1-His198Cys & + & $70-100$ & $80-90$ \\
D1-His198Ala & + & $50-70$ & $50-60$ \\
D1-His198Lys & - & yes, but rapidly & 40 \\
& & photoinhibited & \\
D1-His198Asn & + (poor) & $\sim 50$ & $10-20$ \\
D1-His198Glu & - & $20-25$ & $30-40$ \\
D1-His198Ser & - & $\sim 20$ & $27-33$ \\
D1-His198Thr & - & $\sim 10$ & $16-23$ \\
D1-His198Val & - & $\sim 10$ & $5-10$ \\
D1-His198Gly & & ND & $\leq 5$ \\
D1-His198Leu & - & 0 & 0 \\
D2-His197Gln & + & 40 & 80 \\
D2-His197Ala & + & ND & 50 \\
D2-His197Asn & + (poor) & ND & 20 \\
D2-His197Leu & - & 0 & 0 \\
\hline
\end{tabular}

concentrations of ${ }^{14} \mathrm{C}$-diuron $(57 \mu \mathrm{Ci} / \mu \mathrm{mol})$ in the presence and absence of unlabeled $20 \mu \mathrm{M}$ atrazine to correct for nonspecific binding. The cells were spun down, and the supernatant was counted. The difference (without atrazine) minus (with atrazine) is a specific measure of diuron bound to PSII.

Steady-state rates of oxygen evolution were measured in whole Synechocystis cells as previously described (44).

\section{RESULTS}

Site-Directed Mutations. The first site-directed mutations introduced at D1-His198 and D2-His197 were leucines (59). These were chosen as a test of whether, in PSII, a chlorophyll could be replaced by a pheophytin, forming a heterodimeric special pair in PSII analogous to that observed in the bacterial reaction centers $(36,37)$. Surprisingly, this mutation resulted in the complete loss of the PSII reaction centers in both mutant strains (Table 1), as indicated by the absence of fluorescence induction in the presence of DCMU and hydroxylamine and by the absence of PSII $\mathrm{Q}_{\mathrm{B}}$ binding sites as measured by ${ }^{14} \mathrm{C}$-diuron. A similar loss of reaction center has been reported for the mutant strain D2-His197Tyr (60). The site-directed mutations analyzed in this work are summarized in Table 1. The replacement of His with other residues with alkyl side chains (valine and alanine) gave, in contrast to those strains just mentioned, levels of functional centers 5-10\% and 50-60\%, respectively, of wild type levels on a per cell basis. The D1-His198Ala mutant is competent for photoautotrophic growth and, despite the absence of a coordinating side chain, does not result in the replacement of a chlorophyll with a pheophytin as determined by pigment analysis. This behavior is reminiscent of the recently reported observation of the retention of Bchlorophyll in the special pair primary electron donor of $R b$. sphaeroides reaction centers upon replacement of L-His173 and MHis202 with glycine (39). However, the replacement of D1His198 by Gly, results in a level of functional PSII centers per cell that does not exceed 5\% of wild-type levels.

We report here that a broad range of residues can occupy the D1-His198 site and still allow center assembly and chromophore binding (Table 1). The behavior of the resulting mutants differs from wild type with regard to the absorbance 

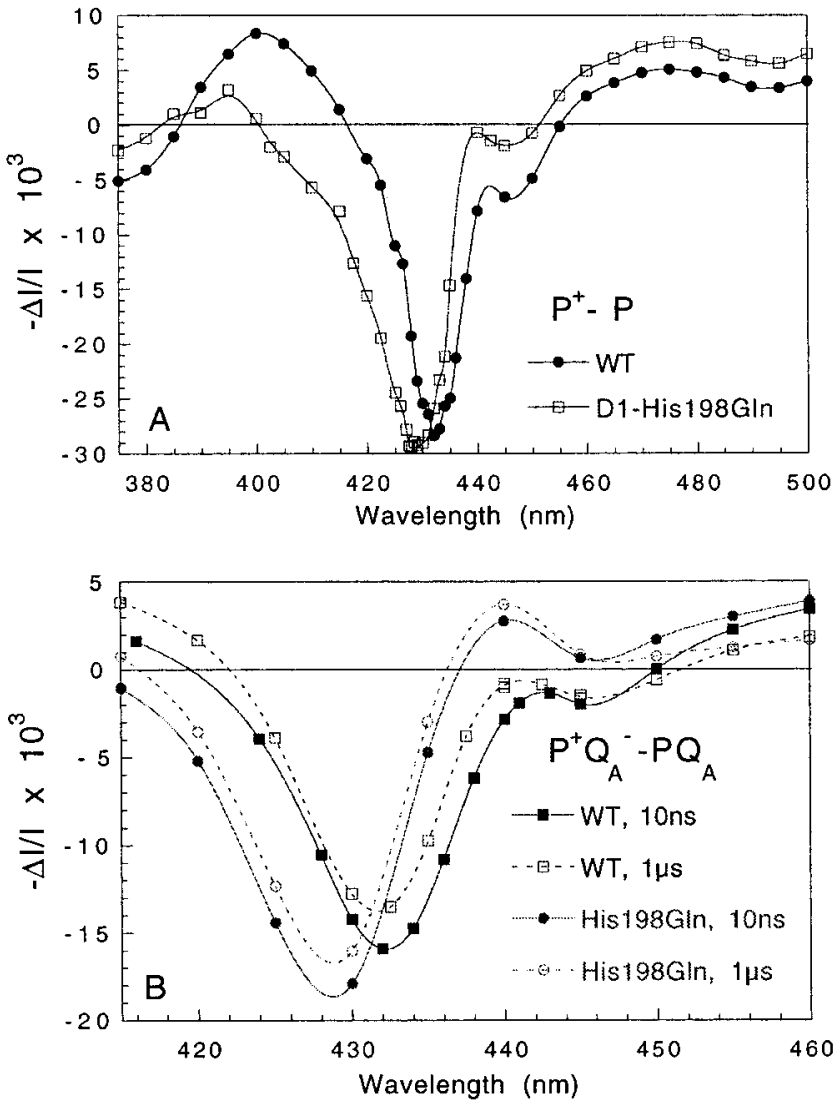

FIGURE 1: (A) $\mathrm{P}^{+}-\mathrm{P}$ difference spectrum measured $1 \mu$ s after a saturating actinic flash on PSII core complexes of WT and mutant strain, D1-His198Gln. The core complexes were suspended at a concentration of $10 \mu \mathrm{g}$ of $\mathrm{Chl} / \mathrm{mL}$ in $20 \mathrm{mM}$ MES, pH 5.9, containing $10 \mu \mathrm{M} \mathrm{K}_{3} \mathrm{Fe}(\mathrm{CN})_{6}$. The spectra were recorded at $298 \mathrm{~K}$ and have been corrected for the contribution of $\mathrm{Q}_{\mathrm{A}}{ }^{-}-\mathrm{Q}_{\mathrm{A}}$. The optical path is $1 \mathrm{~cm}$. (B) $\mathrm{P}^{+} \mathrm{Q}_{\mathrm{A}}{ }^{-}-\mathrm{PQ}_{\mathrm{A}}$ difference spectra measured at $10 \mathrm{~ns}$ (closed symbols) and $1 \mu \mathrm{s}$ (open symbols) after a saturating actinic flash in PSII core complexes from the WT (squares) and the mutant D1-His198Gln strains. The core complexes were suspended at $22 \mu \mathrm{g}$ of $\mathrm{Chl} / \mathrm{mL}$ in $50 \mu \mathrm{L}$ of $20 \mathrm{mM}$ MES, pH 5.9, plus $40 \mu \mathrm{M} \mathrm{K} \mathrm{K}_{3} \mathrm{Fe}(\mathrm{CN})_{6}$. The optical path is $2.5 \mathrm{~mm}$. The spectra were recorded at $298 \mathrm{~K}$.

difference spectra of $\mathrm{P}^{+}-\mathrm{P}$ and the reduction potentials of the primary donor couple $\mathrm{P}^{+} / \mathrm{P}$. These are examined below beginning with the absorbance difference spectra.

$\mathrm{P}^{+}-P$ Difference Spectra. Difference spectra for $\mathrm{P}^{+}-\mathrm{P}$ were measured in the vicinity of the Soret bleaching in the blue region of the spectrum. The spectra shown are measured $1 \mu \mathrm{s}$ after a saturating laser flash and have been corrected for the contribution of $\mathrm{Q}_{\mathrm{A}}{ }^{-}-\mathrm{Q}_{\mathrm{A}}$. A complete difference spectrum in the Soret region is shown for the WT and the D1-His198Gln mutant between 375 and $500 \mathrm{~nm}$ (Figure 1A), while, for the other mutants, only the region close to the maximum bleach is shown (Figure 2). The differences between the spectra are significant, showing for the D1His 198 mutants (Figures 1A,B and 2A) displacements in the bleaching band of up to $3 \mathrm{~nm}$ to the blue (e.g. D1-His198Gln) compared to WT, which is located at $433 \mathrm{~nm}$. There is no apparent correlation between the kinetic behavior of $\mathrm{P}$ (see below) and the shifts in the difference spectra. For example, mutant D1-His198Gln shows the most displaced spectrum and yet shows a reduction potential for $\mathrm{P}^{+} / \mathrm{P}$ that is virtually the same as observed for WT in PS II core complexes (see below).
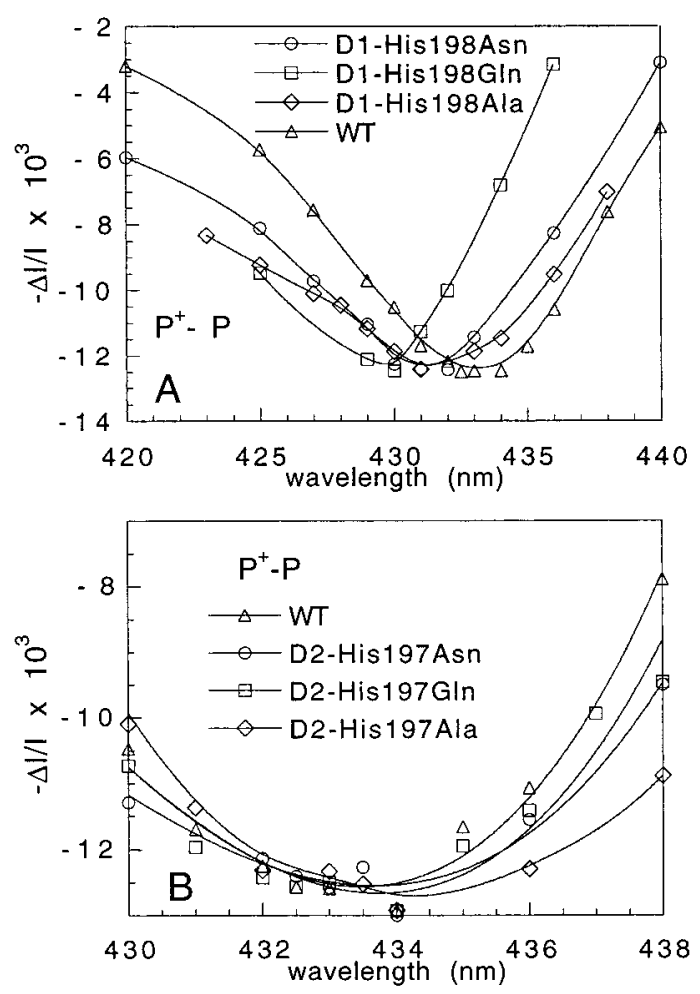

Figure 2: (A, B) $\mathrm{P}^{+}-\mathrm{P}$ difference spectra measured $1 \mu \mathrm{s}$ after a saturating actinic flash on PSII core complexes of WT and strains containing mutations D1-His198Asn, -Gln, -Ala and D2-His197Asn, -Gln, and -Ala. The conditions were the same as for Figure 1A, except $5 \mu \mathrm{g} \mathrm{Chl} / \mathrm{mL}$. The spectra have been corrected for the contribution of $\mathrm{Q}_{\mathrm{A}}{ }^{-}-\mathrm{Q}_{\mathrm{A}}$ and normalized to the WT signal.

The corresponding D2-His197 mutants respond somewhat differently. Their $\mathrm{P}^{+}-\mathrm{P}$ difference spectra are less perturbed (Figure 2B) showing in the Soret some broadening, combined with displacements to the red of the bleaching band by $0.5-$ $1.5 \mathrm{~nm}$, with D2-His197Ala the most red-shifted of the lot. None of the mutations show displacements to the blue as observed at D1-198. As discussed below (see Discussion), we attribute these small displacements to the red of the bleaching maximum to two opposing effects-a small intrinsic displacement to the blue of the $\mathrm{P}_{\mathrm{B}}$ absorbance band from the ligand replacement counterbalanced by an increased stabilization of the $\mathrm{P}^{+}$cation on $\mathrm{P}_{\mathrm{B}}$, which absorbs to longer wavelength than $\mathrm{P}_{\mathrm{A}}$.

The $\mathrm{P}^{+}-\mathrm{P}$ difference spectra for the wild type and D1His198Gln mutant were also measured on a much shorter time scale (10 ns, Figure 1B) to determine if there were any evidence for migration of the cation between $10 \mathrm{~ns}$ and 1 $\mu \mathrm{s}$. A modification of the spectrum in this time range would be an indication of such migration. Figure 1B shows that the difference spectrum of $\mathrm{P}^{+}-\mathrm{P}$ measured in the D1His198Gln mutant, while decaying slightly, is invariant on the time scale of $10 \mathrm{~ns}$ to $1 \mu \mathrm{s}$. This measurement indicates that the reaction center has become fully equilibrated with respect to the location of the $\mathrm{P}^{+}$cation in less than $10 \mathrm{~ns}$. The $\mathrm{P}^{+}-\mathrm{P}$ spectrum is thus representative either of the chlorophyll that has participated in primary charge separation or of the chlorophyll to which the cation has migrated in $\ll 10 \mathrm{~ns}$. As the reaction center triplet forms on the time scale of 60-200 ns (61-63), upon illumination with $\mathrm{Q}_{\mathrm{A}}$ reduced, the cation radical detected at $10 \mathrm{~ns}$ is likely to be the source 


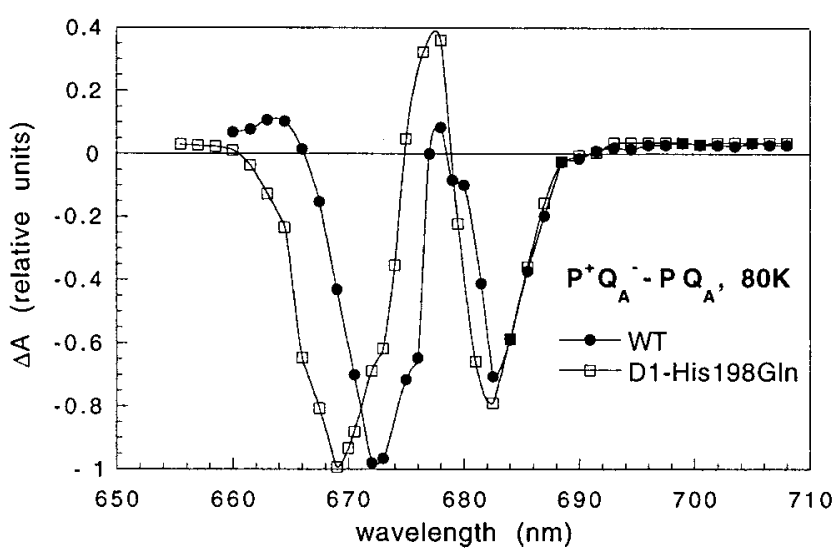

FIGURE 3: $\mathrm{P}^{+} \mathrm{Q}_{\mathrm{A}}{ }^{-}-\mathrm{PQ}_{\mathrm{A}}$ difference spectra measured at $80 \mathrm{~K}$. The PSII core complexes of the WT and D1-His198Gln mutants were suspended at a concentration of about $10 \mu \mathrm{g}$ of $\mathrm{Chl} / \mathrm{mL}$ in $50 \mathrm{mM}$ MES, pH 6.5, $10 \mathrm{mM} \mathrm{MgCl} 2,20 \mathrm{mM} \mathrm{CaCl}_{2}, 0.02 \% \beta$ - dodecyl maltoside, and $60 \%$ glycerol containing $3 \mathrm{mM} \mathrm{K} \mathrm{K}_{3} \mathrm{Fe}(\mathrm{CN})_{6}$. The decay of the flash-induced absorbance changes was fitted with two exponential phases $\left(t_{1 / 2} \approx 1.8 \mathrm{~ms}(\approx 40 \%)\right.$ and $t_{1 / 2} \approx 6.3 \mathrm{~ms}$ $(\approx 57 \%)$ ) plus a nondecaying component of $\approx 3 \%$. The sum of the amplitudes is depicted as a function of the wavelength. The spectra were normalized to the bleaching minimum.

of the cation that participates in charge recombination to generate the triplet.

The $\mathrm{P}^{+} \mathrm{Q}_{\mathrm{A}}{ }^{-}-\mathrm{PQ}_{\mathrm{A}}$ difference spectra in the $\mathrm{Q}_{y}$ region were also compared at $80 \mathrm{~K}$ in core complexes isolated from the wild type and D1-His198Gln mutant (Figure 3). The spectrum of $\mathrm{Q}_{\mathrm{A}}{ }^{-}-\mathrm{Q}_{\mathrm{A}}$ in the $\mathrm{Q}_{y}$ region was examined in these complexes in Stewart et al. (64). The contribution of this difference spectrum to that of $\mathrm{P}^{+} \mathrm{Q}_{\mathrm{A}}{ }^{-}-\mathrm{PQ}_{\mathrm{A}}$ is approximately $1 \%$ between 660 and $680 \mathrm{~nm}$ and $5 \%$ between 680 and 690 nm. The difference spectrum of Figure 3 is therefore primarily $\mathrm{P}^{+}-\mathrm{P}$. This spectrum shows bleaching (in WT) at 672.5 and $682-683 \mathrm{~nm}$ and a positive peak at $678 \mathrm{~nm}$. The form of the spectrum has been explained by a band bleaching associated with the oxidation of $\mathrm{P}$ accompanied by a $\mathrm{P}^{+}$induced electrochromic band shift of a neighboring chlorophyll (30). Thus, in the WT spectrum, there is either a bleaching at $672.5 \mathrm{~nm}$ and a blue-shift of a $682 \mathrm{~nm}$-centered band or a bleaching at 682-683 and a red-shift of a 675 nm-centered band Upon replacement of D1-His198 with GIn, a displacement to the blue of $3 \mathrm{~nm}$, as in the Soret, is observed for the $672.5 \mathrm{~nm}$ band. This is the larger of the two bleached bands observed in the spectrum. The other bleached band, located at $682-683 \mathrm{~nm}$, is unaffected by the mutation.

There are several possible explanations for the mutationinduced spectral shifts. These are (1) that the cation is predominantly localized on the chlorophyll with the mutated axial ligand which absorbs at and is consequently bleached at $672.5 \mathrm{~nm}$ (in WT) and (2) that the cation is localized on a different chlorophyll. In this latter case there are two subcases: (a) The cation is localized on the chlorophyll with the $682-683 \mathrm{~nm}$ band producing an electrochromic shift in the spectrum of the nearby chlorophyll with the mutated ligand. (b) The mutation causes a redistribution of the charge among the reaction center chlorophylls, causing different chlorophylls to contribute to the $\mathrm{P}^{+}-\mathrm{P}$ difference spectrum.

Tyr ${ }^{\circ}$ Tyr Difference Spectra. To distinguish among these possibilities, we looked for an independent method to determine whether these mutations have actually produced a displacement of the spectrum of one of the reaction center

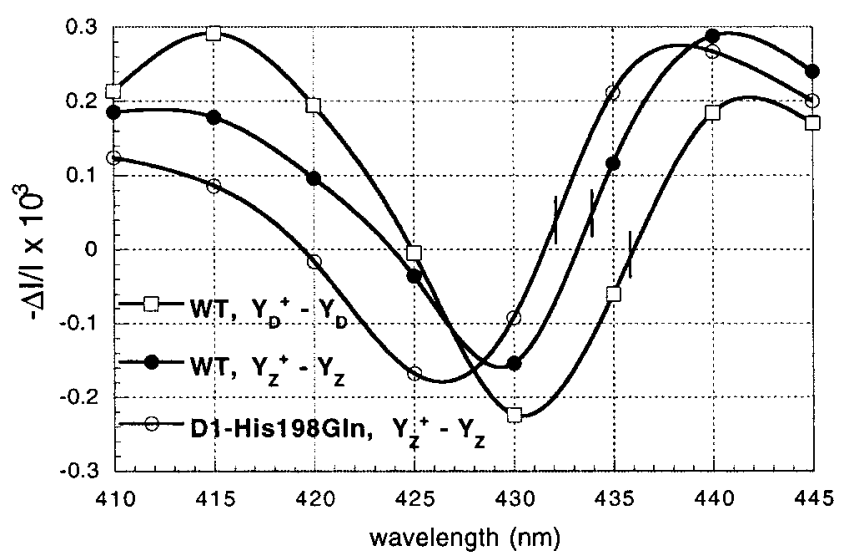

FIGURE 4: $Y_{Z} \bullet-Y_{Z}$ and $Y_{D} \bullet-Y_{D}$ difference spectra measured in PSII core complexes isolated from the WT and D1-His198Gln

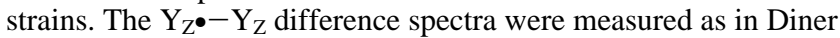
and de Vitry (49) at a concentration of $10 \mu \mathrm{g}$ of Chl $/ \mathrm{mL}$ in $20 \mathrm{mM}$ MES, pH 5.9, $20 \mu \mathrm{M}$ benzidine, and $10 \mu \mathrm{M} \mathrm{K}{ }_{3} \mathrm{Fe}(\mathrm{CN})_{6}$. Shown is the difference $0.5-5 \mathrm{~ms}$ after a saturating actinic flash. This difference minimizes the contribution of $\mathrm{Q}_{\mathrm{A}}{ }^{-}-\mathrm{Q}_{\mathrm{A}}$. The $\mathrm{Y}_{\mathrm{D}} \bullet-\mathrm{Y}_{\mathrm{D}}$ difference spectrum was measured as in Diner et al. (51) with the core complexes suspended in $100 \mathrm{mM}$ Na phosphate and $400 \mathrm{mM}$ $\mathrm{Na}$ formate, $\mathrm{pH} 6.0$, containing $100 \mu \mathrm{M} \mathrm{K}{ }_{3} \mathrm{Fe}(\mathrm{CN})_{6}$ and $100 \mu \mathrm{M}$ $\mathrm{K}_{4} \mathrm{Fe}(\mathrm{CN})_{6}$. The $\mathrm{Y}_{\mathrm{D}} \bullet-\mathrm{Y}_{\mathrm{D}}$ difference spectrum was normalized to the amplitude of the red-shifted component of the $Y_{Z^{\bullet}}-Y_{Z}$ difference spectrum.

chlorophylls and to determine which one that was. One way that we have found to do so is via the oxidation of the PSII redox-active tyrosines, $\mathrm{Y}_{\mathrm{Z}}$ and $\mathrm{Y}_{\mathrm{D}}$. Absorbance changes associated with these oxidations are observed in the red (65) and the blue regions $(49,66)$ of the visible spectrum that clearly arise from chlorophyll band shifts in the $\mathrm{Q}_{y}$ and Soret optical transitions, respectively. While the interpretation of these band shifts remains controversial (electrochromism (51, $67,68)$ versus proton displacement within a hydrogen bond (69)), there is no disagreement as to their arising from one or more of the reaction center chlorophylls. These are likely the electronic counterparts of differences observed in the vibrational spectra for $\mathrm{Y}_{\mathrm{Z}} \bullet-\mathrm{Y}_{\mathrm{Z}}(70,71)$ and $\mathrm{Y}_{\mathrm{D}} \bullet-\mathrm{Y}_{\mathrm{D}}(72)$, attributed to the keto $\mathrm{C}_{9}=\mathrm{O}$ groups of $\mathrm{P}$.

The wild-type $\mathrm{Y}_{\mathrm{Z}} \bullet-\mathrm{Y}_{\mathrm{Z}}$ associated red band shift in the Soret (Figure 4) shows an inflection point at $\sim 434 \mathrm{~nm}$, close to the bleaching minimum observed for $\mathrm{P}^{+}-\mathrm{P}$. The entire band shift in the D1-His198Gln mutant is displaced by $2-3$ $\mathrm{nm}$ to the blue relative to that of the wild type just as we observed for the $\mathrm{P}^{+}-\mathrm{P}$ difference spectrum of the same mutant. This observation implies that a single chlorophyll molecule dominates the $\mathrm{Y}_{\mathrm{Z}}$-associated Soret band shift. Homology models of PSII (10) show the chlorophyll coordinated by D1-His198 $\left(\mathrm{P}_{\mathrm{A}}\right)$ to be closer to $\mathrm{Y}_{\mathrm{Z}}(\sim 10 \AA)$ than is $\mathrm{B}_{\mathrm{A}}(\sim 14 \AA) . \mathrm{P}_{\mathrm{A}}$ is also oriented with the axis of its $\mathrm{Q}_{y}$ transition, passing through pyrrole rings I and III, in the plane of the membrane and pointing toward $\mathrm{Y}_{\mathrm{Z}}$. This orientation could explain why the oxidized tyrosine causes a $Q_{y}(65)$ and a Soret band shift should this band shift be of electrochromic origin. $\mathrm{Y}_{\mathrm{Z}}$ is more closely aligned with the $\mathrm{Q}_{x}$ axis passing through rings $\mathrm{II}$ and $\mathrm{IV}$ of $\mathrm{B}_{\mathrm{A}}$. The chlorophyll $\mathrm{Q}_{x}$ electronic transition is very weak and may not result in a change in dipole strength between the ground and excited states. We will indicate in the Discussion section why we think this signal is electrochromic and associated with the plus charge produced upon $\mathrm{Y}_{\mathrm{Z}}$ oxidation. The plus 
charge responsible for the electrochromism is certainly not localized on the tyrosyl radical but on a nearby residue or residues that act as proton acceptor.

The D1-His198 ligated $\mathrm{P}_{\mathrm{A}}$ chlorophyll is therefore the most significant optical probe of $\mathrm{Y}_{\mathrm{Z}}$ oxidation. That the D1His198Gln mutation induces the same displacement of the

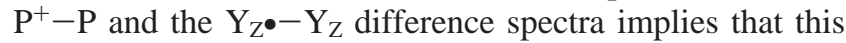
mutation has indeed modified the ground-state absorbance spectrum of $\mathrm{P}_{\mathrm{A}}$, coordinated by D1-198. This observation eliminates the alternative possibility mentioned above of a mutation-induced modified charge distribution. The dominance of the bleached $433 \mathrm{~nm}$ band in the Soret and the $672.5 \mathrm{~nm}$ band in the $\mathrm{Q}_{y}$ region $\mathrm{P}^{+}-\mathrm{P}$ difference spectra is consistent with both of these bearing the oscillator strength of the chlorophyll that becomes oxidized. As both are shifted by the D1-His198Gln mutation, it is likely that the reaction center chlorophyll cation is predominantly localized on $\mathrm{P}_{\mathrm{A}}$ at $\geq 10 \mathrm{~ns}$ following primary charge separation.

An examination of the $Y_{D} \bullet-Y_{D}$ difference spectrum (Figure 4) shows an inflection point at $436 \mathrm{~nm}$, indicating that the optical probe for the oxidation of this tyrosine is a chlorophyll other than $\mathrm{P}_{\mathrm{A}}$. Homology modeling and the $C_{2}$ symmetry of the reaction center point to the D2-His197 coordinated $\mathrm{P}_{\mathrm{B}}$ chlorophyll as being the most likely optical probe for this tyrosine $(10,17,73)$. The difference in the spectra for $Y_{Z} \bullet-Y_{Z}$ and $Y_{D} \bullet-Y_{D}$ also implies that the chlorophylls are either excitonically decoupled or only very weakly coupled, unlike their homologues in the bacterial reaction centers. As $\mathrm{P}_{\mathrm{A}}$ is the principal optical probe for $\mathrm{Y}_{Z^{\bullet}-}$ $Y_{Z}$, then by symmetry $P_{B}$, peaking at $436 \mathrm{~nm}$ in the Soret, is the optical probe for $Y_{D}-Y_{D}$.

${ }^{3} \mathrm{P}-{ }^{1} \mathrm{P}$ Difference Spectra. As pointed out in the Introduction, one of the puzzles associated with PSII function is the unexpected orientation with respect to the membrane plane of the spin-polarized triplet, ${ }^{3} \mathrm{P}(15,24,74)$. Rather than being oriented with its $g_{z}$ triplet axis lying in the membrane plane as in the bacterial reaction centers $(75,76)$, this g-tensor component for ${ }^{3} \mathrm{P}$ is oriented at $60^{\circ}$ with respect to the membrane normal (ring plane $30^{\circ}$ with respect to the membrane plane). This orientation is identical to the orientation of the monomeric Bchlorophylls of the bacterial reaction centers $(15,24)$ and has led to a number of different proposals associating ${ }^{3} \mathrm{P}$ with either a homologous PSII monomeric accessory chlorophyll, $\mathrm{B}_{\mathrm{A}}$ or $\mathrm{B}_{\mathrm{B}}$, or a rotated PSII homologue of one of the $\mathrm{P}_{\mathrm{A}}$ and $\mathrm{P}_{\mathrm{B}}$ special pair Bchlorophylls (see Introduction and Discussion).

The results presented above support the idea that the sitedirected mutations at D1-198 directly modify the absorbance spectrum of the $\mathrm{P}_{\mathrm{A}}$ chlorophyll coordinated by this ligand. To determine whether the reaction center charge recombination-induced triplet was localized on this same chlorophyll, we looked for alterations in the spectroscopic properties of the triplet, detected by both optical and magnetic resonance techniques.

The triplet was generated at both 5 and $80 \mathrm{~K}$ by flash excitation in the presence of dithionite, conditions under which $\mathrm{Q}_{\mathrm{A}}$ is reduced prior to illumination. The ${ }^{3} \mathrm{P}-{ }^{1} \mathrm{P}$ triplet minus singlet difference spectrum was measured in the red in PSII core complexes of both the D1-His198Gln mutant and the wild type. As seen in Figure 5A, the difference spectra of both complexes are superimposable at $80 \mathrm{~K}$ and, if at all at $5 \mathrm{~K}$, show a slight displacement opposite in sign
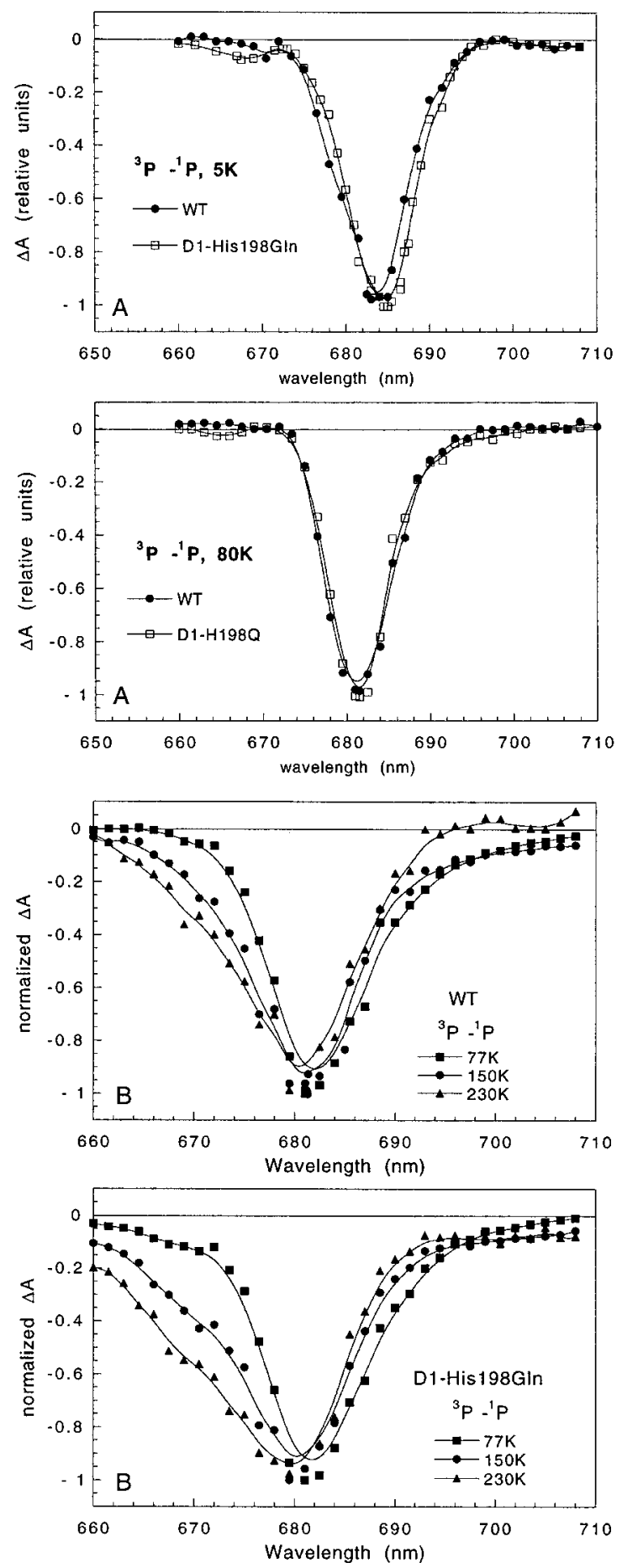

Figure 5: (A) Top: ${ }^{3} \mathrm{P}-{ }^{1} \mathrm{P}$ difference spectrum measured at $5 \mathrm{~K}$ as in Hillmann et al. (30) using PSII core complexes isolated from WT and D1-His198Gln (D1-H198Q). The core complexes were suspended in the same medium as in Figure 3 at about $10 \mu \mathrm{g}$ of $\mathrm{Chl} / \mathrm{mL}$ except that instead of adding $\mathrm{K}_{3} \mathrm{Fe}(\mathrm{CN})_{6}$ the sample was reduced with $10 \mathrm{mM}$ dithionite. The decay of the flash-induced absorbance changes was fitted with two exponentials $\left(t_{1 / 2} \approx 1.0\right.$ $\mathrm{ms}$ and $t_{1 / 2} \approx 5 \mathrm{~ms}$ ). The sum of the amplitudes is depicted as a function of the wavelength. The spectra were normalized to the bleaching minimum which corresponds to a $\Delta A$ of 0.02 . Bottom: ${ }^{3} \mathrm{P}-{ }^{1} \mathrm{P}$ difference spectrum measured at $80 \mathrm{~K}$ using PSII core complexes isolated from WT and D1-His198Gln. The conditions were the same as for the upper spectra. (B) ${ }^{3} \mathrm{P}-{ }^{1} \mathrm{P}$ difference spectrum measured at 77,150 , and $230 \mathrm{~K}$ using PSII core complexes isolated from WT and D1-His198Gln (D1-H198Q). The conditions were the same as for (A). The triplet yields at 150 and $230 \mathrm{~K}$ are respectively $43 \%$ and $27 \%$ of that at $77 \mathrm{~K}$. The bleaching maximum at $77 \mathrm{~K}$ corresponds to a $\Delta A$ of 0.01 . 
to the difference spectrum for $\mathrm{P}^{+}-\mathrm{P}$ measured at $80 \mathrm{~K}$. The absence of an effect of the D1-His198Gln mutation on the main bleaching band of the ${ }^{3} \mathrm{P}-{ }^{1} \mathrm{P}$ difference spectrum argues that the triplet is not localized on $\mathrm{P}_{\mathrm{A}}$ at $\leq 80 \mathrm{~K}$.

There is, however, a small sideband observed between 665 and $672 \mathrm{~nm}$ that appears to be displaced $(\sim 3 \mathrm{~nm})$ to shorter wavelength by the D1-His198Gln mutation at these temperatures. As there is no $\mathrm{P}^{+}$generated under the conditions of this experiment, this feature may reflect the loss of a weak exciton interaction between $\mathrm{B}_{\mathrm{A}}$ and $\mathrm{P}_{\mathrm{A}}$.

Noguchi et al. (27, 28), Kamlowski et al. (62), and Bosch et al. (77) have reported a temperature-dependent transfer of the PSII reaction center triplet, with the first two groups proposing an energy gap of $8-13 \mathrm{meV}$ between the triplet state energies. Noguchi et al. $(27,63)$ have suggested that the triplet could migrate from ${ }^{3} \mathrm{P} 680$ to another chlorophyll designated ChlT at low temperature or be formed directly on ChlT. The ${ }^{3} \mathrm{P}-{ }^{1} \mathrm{P}$ spectrum was therefore examined at temperatures above $80 \mathrm{~K}$ to determine if the triplet localization might include $\mathrm{P}_{\mathrm{A}}$ at higher temperatures. The ${ }^{3} \mathrm{P}-{ }^{1} \mathrm{P}$ difference spectra were compared at 77,150 , and $230 \mathrm{~K}$ for the wild type and the D1-His198Gln (Figure 5B). While the spectra broaden somewhat with temperature, it is clear that in the case of the D1-His198Gln mutant there is a marked shoulder that appears on the short-wavelength side of the bleached band consistent with an increased contribution of $\mathrm{P}_{\mathrm{A}}$ at elevated temperature. We attribute the shoulder, in the case of the mutant, to the $3 \mathrm{~nm}$ displacement to the blue of the ground-state absorbance spectrum of $\mathrm{P}_{\mathrm{A}}$ from 672.5 to $669.5 \mathrm{~nm}$.

EPR Spectra of Spin-Polarized Triplet. The spin-polarized triplet, ${ }^{3} \mathrm{P}$, was also generated with $\mathrm{Q}_{\mathrm{A}}$ reduced by continuous illumination in the EPR cavity and detected by EPR at $5 \mathrm{~K}$. Should the D1-198 mutations alter the localization of the triplet or the coordination symmetry of the chlorophyll on which the triplet were localized, then $\mathrm{D}$ and $\mathrm{E}$, the axial and rhombic zero field splitting parameters, respectively, might be altered. Figure 6 shows a comparison of the spin-polarized triplet spectra for the wild type and the D1-His198Ala strains. These spectra as well as the others, which are all virtually identical (see Table 2), indicate that, at least at liquid helium temperature, no differences exist in the zero field splitting parameters of the spin-polarized triplets or in the optical spectra, arguing that the chlorophyll that is bleached upon triplet formation is not the same one as is modified by the mutation.

The $D$ and $E$ zero field splitting parameters and the AEEAAE polarization pattern reported here and in Coleman et al. (42) are indicative of a reaction center spin-polarized triplet formed by charge recombination (for review see ref 78). The spectra are virtually identical to those reported by van Mieghem and Rutherford (24) and are consistent with the localization of the triplet on a monomeric chlorophyll (19). There is no detectable contribution from triplets formed by intersystem crossing in the CP43 and CP47 core antenna. No triplet states are observed under oxidizing conditions. Furthermore, the temperature dependence of triplet formation (decreasing with increasing temperature, Figure 5B) and the light saturation behavior for ${ }^{3} \mathrm{P}$ all point to a reaction center origin for the triplet. We conclude, therefore, that the optical spectra described above arise exclusively from the reaction center triplet.
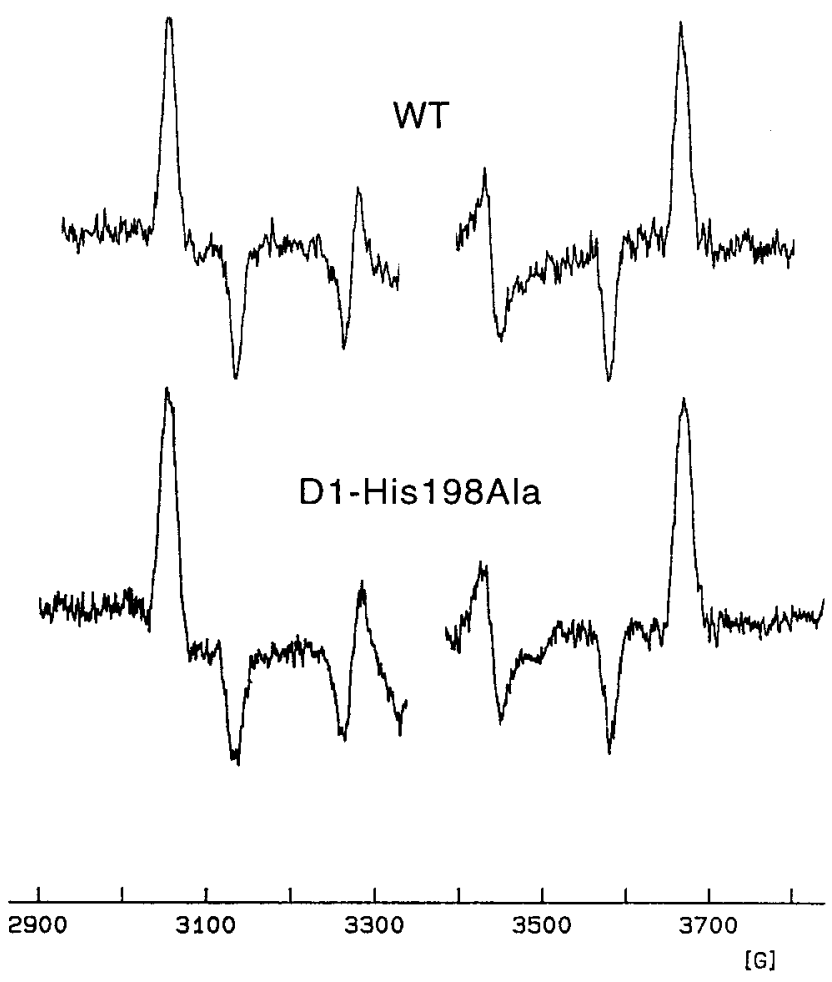

FIGURE 6: Spin-polarized EPR spectra of the ${ }^{3} \mathrm{P}$ generated under reducing conditions by continuous illumination at $5 \mathrm{~K}$ in PSII core complexes from the WT (upper) and the mutant D1-His198Ala (lower) strains. These are light-minus-dark difference spectra (see Materials and Methods). The PSII core complexes are at a concentration of $\sim 1 \mathrm{mg}$ of $\mathrm{Chl} / \mathrm{mL}$. EPR conditions: temperature, $4.2 \mathrm{~K}$; microwave power, $63 \mu \mathrm{W}(35 \mathrm{~dB})$; Sweep width: $1000 \mathrm{G}$; Frequency: $9.416 \mathrm{GHz}$; Modulation frequency: $100 \mathrm{kHz}$, modulation amplitude, $20 \mathrm{G}$; time constant, $82 \mathrm{~ms}$; number of scans, 10 .

\begin{tabular}{rcc}
\hline Table 2: & Spin-Polarized Triplet Zero-Field-Splitting Parameters \\
\hline \multicolumn{1}{c}{ strain } & $|D|\left(\mathrm{cm}^{-1}\right)$ & $|E|\left(\mathrm{cm}^{-1}\right)$ \\
\hline WT & $287 \times 10^{-4}$ & $44 \times 10^{-4}$ \\
D1-His198Ala & $288 \times 10^{-4}$ & $44 \times 10^{-4}$ \\
D1-His198Cys & $286 \times 10^{-4}$ & $44 \times 10^{-4}$ \\
D1-His198Gln & $289 \times 10^{-4}$ & $44 \times 10^{-4}$ \\
D1-His198Glu & $289 \times 10^{-4}$ & $44 \times 10^{-4}$ \\
\hline
\end{tabular}

Redox and Kinetic Properties of Mutations. In contrast to the observations in bacterial reaction centers, where the redox properties of the primary donor were hardly affected by replacement of the coordinating histidines with Gly, Asn, and Ser $(38,39)$, we find in PSII substantial effects of ligand substitution. The relative reduction potential of the redox couple $\mathrm{P}^{+} / \mathrm{P}$ was determined by two methods: (a) by charge recombination in whole cells and in core complexes using fluorescence and optical spectroscopy, respectively; (b) by analysis of the kinetics of reduction of $\mathrm{P}^{+}$by $\mathrm{Y}_{\mathrm{Z}}$ in core complexes using optical spectroscopy (see Figures 7 and 8).

Charge recombination between the donor and acceptor sides of the PSII reaction center occurs between $\mathrm{P}^{+}$and $\mathrm{Q}_{\mathrm{A}}{ }^{-}$, with the rate determined by the equilibrated concentration of each of these. The intrinsic rate constant for $\mathrm{P}^{+} \mathrm{Q}_{\mathrm{A}}{ }^{-}$ recombination in the absence of such equilibration, $k_{\mathrm{in}}$, was found to be $700 \mathrm{~s}^{-1}$ in PSII core complexes isolated from the D1-Tyr161Phe strain, which lacks the secondary electron donor, $\mathrm{Y}_{\mathrm{Z}}$, and from which the secondary quinone electron 

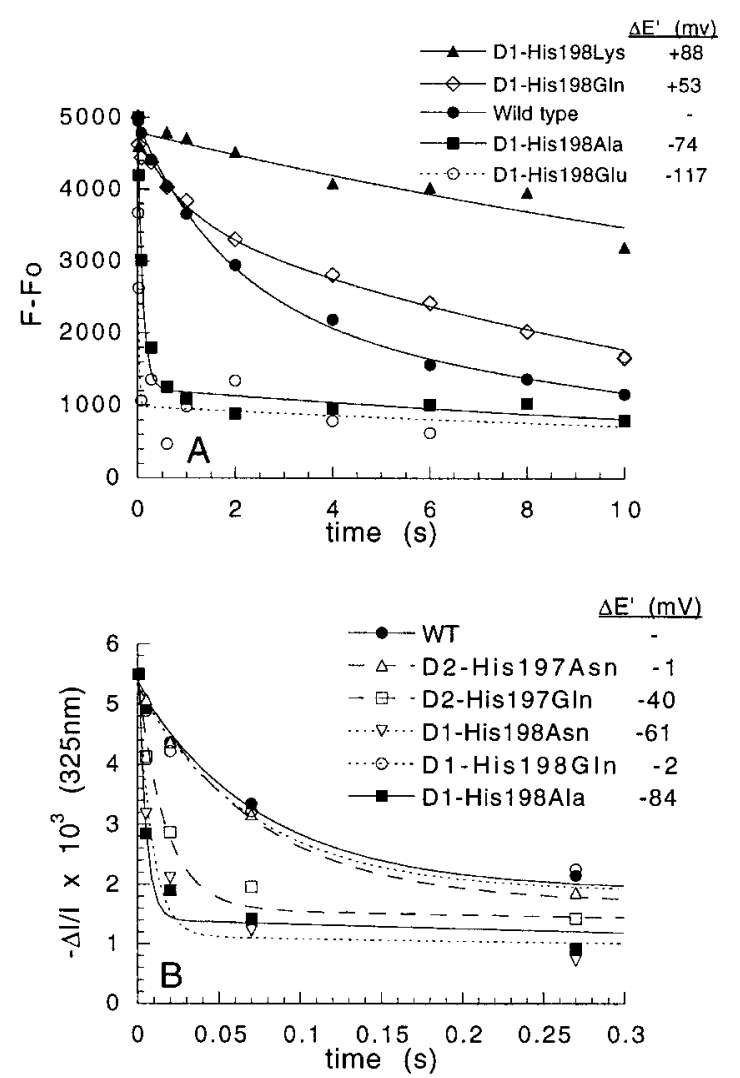

FIGURE 7: (A) Fluorescence relaxation in wild-type and mutant strains following a single flash in the presence of DCMU as described in (53). The cells were suspended at a concentration of 0.9 OD $(730 \mathrm{~nm})$ in BG-11 medium (117) plus $50 \mathrm{mM}$ HEPES, $\mathrm{pH} \mathrm{7.5}$, and pretreated for $10 \mathrm{~min}$ with $0.3 \mathrm{mM} p$-benzoquinone and $0.3 \mathrm{mM} \mathrm{K}_{3} \mathrm{Fe}(\mathrm{CN})_{6}$. DCMU $(40 \mu \mathrm{M})$ was added, and the fluorescence yield was monitored by following a saturating actinic flash by a train of detecting flashes given at the indicated times. The data were normalized to the same initial value at $500 \mu \mathrm{s}$ after the actinic flash. (B) Kinetics of charge recombination between $\mathrm{Q}_{\mathrm{A}}{ }^{-}$and the electron donor side in wild-type and mutant PSII core complexes at $\mathrm{pH} 5.7$, measured at $325 \mathrm{~nm}$, an absorbance maximum for $\mathrm{Q}_{\mathrm{A}}{ }^{-}-\mathrm{Q}_{\mathrm{A}}$. His was replaced by Asn, Gln, and Ala at codons D2-197 and D1-198. A saturating actinic flash was followed by a train of detecting flashes at the indicated times. PSII core complexes were suspended in $20 \mathrm{mM}$ MES, pH 5.7, plus $1 \mu \mathrm{M} \mathrm{K} \mathrm{K}_{3} \mathrm{Fe}(\mathrm{CN})_{6}$ at a concentration of $\sim 7 \mu \mathrm{g}$ of $\mathrm{Chl} / \mathrm{mL}$. The data for the mutant core complexes were normalized to the initial value of the WT sample, measured at $500 \mu$ s after the actinic flash. Optical path: 1 $\mathrm{cm}$.

acceptor, $\mathrm{Q}_{\mathrm{B}}$, was extracted in the course of isolation in the presence of detergent (50). In isolated PSII core complexes, lacking the secondary quinone electron acceptor, $\mathrm{Q}_{\mathrm{B}}$, and an artificial electron acceptor, and in whole cells in the presence of $\mathrm{DCMU}, \mathrm{Q}_{\mathrm{A}}{ }^{-}$is oxidized solely by charge recombination. The rate of charge recombination is much slower with $\mathrm{Y}_{\mathrm{Z}}$ present $(>10 \mathrm{~ms}$ ) than the rate at which the oxidizing equivalent is equilibrated on the donor side of the reaction center $(<200 \mu \mathrm{s})$. Consequently, the rate of charge recombination, in the presence of DCMU and with the secondary and tertiary donors intact, is determined by the equilibrated concentration of $\mathrm{P}^{+}$. The distance from $\mathrm{Q}_{\mathrm{A}}^{-}$to $\mathrm{Y}_{\mathrm{Z}^{\bullet}}$ and to the Mn cluster is too great for $\mathrm{Y}_{\mathrm{Z}^{\bullet}} \mathrm{Q}_{\mathrm{A}}{ }^{-}$or $\mathrm{S} 2$ $\mathrm{Q}_{\mathrm{A}}{ }^{-}$recombination to be kinetically competitive (Rappaport, F., Guergova-Kuras, M., Nixon, P. J., Diner. B. A., and Lavergne J., manuscript submitted). The lower the equilibrium constants governing the overall equilibrium,

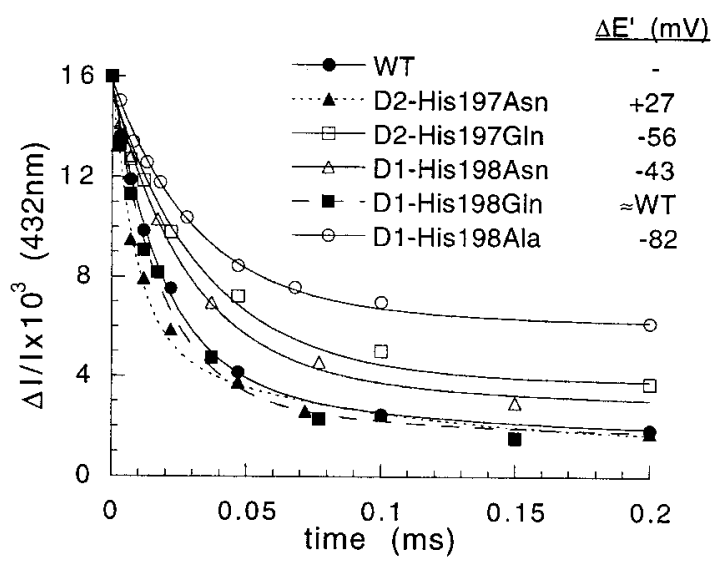

FIGURE 8: Kinetics of reduction of $\mathrm{P}^{+}$measured at $432 \mathrm{~nm}$ at $\mathrm{pH}$ 5.7 in the same wild-type and mutant PSII core complexes as in Figure 7B. A saturating flash was followed by a train of detecting flashes at the indicated times. PSII core complexes were suspended in $20 \mathrm{mM}$ MES, pH 5.7, plus $10 \mu \mathrm{M} \mathrm{K} \mathrm{K}_{3} \mathrm{Fe}(\mathrm{CN})_{6}$ at a concentration of $\sim 5 \mu \mathrm{g} \mathrm{Chl} / \mathrm{mL}$. The results for the mutant complexes were normalized to those of the wild type at a delay of $1 \mu \mathrm{s}$. These kinetics have not been corrected for the formation of $\mathrm{Y}_{\mathrm{Z} \cdot \text {. Optical }}$ path: $1 \mathrm{~cm}$.

$$
\mathrm{S} 1 \mathrm{Y}_{\mathrm{Z}} \mathrm{P}^{+} \stackrel{K_{\text {zp }}}{\rightleftharpoons} \mathrm{S}_{1} \mathrm{Y}_{\mathrm{Z}}^{+} \mathrm{P} \stackrel{K_{\mathrm{sz}}}{\rightleftharpoons} \mathrm{S} 2 \mathrm{Y}_{\mathrm{Z}} \mathrm{P}
$$

(S1 and S2 are two successive oxidation states of the Mn cluster (79)), the higher the concentration of $\mathrm{P}^{+}$and the higher the observed rate $\left(V_{\mathrm{obs}}\right)$ of charge recombination, expressed in eq 1 in terms of the donor side equilibrium constants $\left(K_{\mathrm{zp}}\right.$ and $\left.K_{\mathrm{sz}}\right)$ and $k_{\text {in }}$. We assume $k_{\text {in }}$, to a first approximation, to be independent of the mutation. This assumption is supported by the observations of Lin et al. (80), who have reported only a weak dependence of the rate of charge recombination between $\mathrm{Q}_{\mathrm{A}}^{-}$and $\mathrm{P} 870^{+}$on the reduction potential of $\mathrm{P} 870^{+} / \mathrm{P} 870$. Any increase of $k_{\text {in }}$ with $\mathrm{E}_{\mathrm{P}^{+} / \mathrm{P}}^{\prime}$ would if anything lead to an underestimate of $K_{\mathrm{zp}}$.

$$
\begin{gathered}
V_{\mathrm{obs}}=k_{\mathrm{in}}\left[1 /\left(K_{\mathrm{zp}}\left(1+K_{\mathrm{sz}}\right)+1\right)\right] \\
\Delta E^{\prime}=59 \log \left(K_{\mathrm{zp}_{\mathrm{mut}}} / K_{\mathrm{zp}_{\mathrm{wt}}}\right) \\
K_{\mathrm{zp}_{\mathrm{mut}}} / K_{\mathrm{zp}_{\mathrm{wt}}}=\left[\left(k_{\mathrm{in}} / V_{\mathrm{obs}_{\mathrm{mut}}}\right)-1\right] /\left[\left(k_{\mathrm{in}} / V_{\mathrm{obs}_{\mathrm{wt}}}\right)-1\right]
\end{gathered}
$$

A single flash was given to whole cells in the presence of DCMU and the rate of relaxation of the chlorophyll fluorescence yield examined (Figure 7A, Table 3). In whole cells of Synechocystis 6803, the fluorescence yield is an approximately linear indicator of the redox state of the primary quinone electron acceptor, $\mathrm{Q}_{\mathrm{A}}$ (53). The higher the fluorescence yield, the more reduced $\mathrm{Q}_{\mathrm{A}}$. Figure 7A and Table 3 show the kinetics of charge recombination, observed in whole cells of Synechocystis strains containing mutations at D1-His198 and D2-His197. When the D1-198 mutants are compared to WT (His), the relative rates range from slower (Lys), to similar (Gln), to faster (Ala, Cys, Ser, Glu). It is likely that the mutations at these sites are an exclusive indicator of an altered $K_{\mathrm{zp}}$ rather than $K_{\mathrm{sz}}$, the reactions of which occur at a distance from the primary donor. Those mutants showing a higher rate of recombination, compared to wild type, therefore reflect a stabilization of $\mathrm{P}^{+}$(negative $\Delta E^{\prime}$, Table 3) while those that are slower reflect a destabilization (positive $\Delta E^{\prime}$ ). 
Table 3: Kinetics of Charge Recombination

\begin{tabular}{|c|c|c|c|c|c|c|}
\hline \multirow[b]{2}{*}{ strain } & \multicolumn{3}{|c|}{ cells $^{a}$} & \multicolumn{3}{|c|}{ core complexes ${ }^{b}$} \\
\hline & $A_{1}$ & $k\left(\mathrm{~s}^{-1}\right)$ & $\Delta E^{\prime}(\mathrm{mV})\left(\mathrm{P}^{+} / \mathrm{P}\right)$ & $A_{1}$ & $k\left(\mathrm{~s}^{-1}\right)$ & $\Delta E^{\prime}(\mathrm{mV})\left(\mathrm{P}^{+} / \mathrm{P}\right)^{c}$ \\
\hline WT & 0.51 & 0.56 & & 0.60 & 13.3 & \\
\hline D1-His198Ala & 0.75 & 9.84 & -74 & 0.83 & 220 & -84 \\
\hline D1-His198Asn & & & & 0.81 & 117 & -61 \\
\hline D1-His 198Cys & 0.83 & 11.1 & -77 & & & \\
\hline D1-His198Gln & 0.77 & 0.072 & +53 & 0.61 & 14.3 & -2 \\
\hline D1-His 198Glu & 0.80 & 49.4 & -117 & & & \\
\hline D1-His 198Lys & 0.61 & 0.028 & +88 & & & \\
\hline D1-His198Ser & 0.79 & 42.2 & -112 & & & \\
\hline D2-His 197Ala & 0.76 & 1.85 & $-31(-19)$ & & & \\
\hline D2-His 197Asn & & & & 0.66 & 14.1 & -1 \\
\hline D2-His 197Gln & & & & 0.70 & 58.5 & -40 \\
\hline
\end{tabular}

${ }^{a}$ In cells, recombination occurs between $\mathrm{Q}_{\mathrm{A}}{ }^{-}$and $\mathrm{P}^{+}$in equilibrium with $\mathrm{S} 2$ and $\mathrm{Y}_{\mathrm{Z}}$, with measurement by fluorescence yield relaxation (Figure 7A). ${ }^{b}$ In core complexes, recombination occurs between $\mathrm{Q}_{\mathrm{A}}^{-}$and $\mathrm{P}^{+}$in equilibrium with $\mathrm{Y}_{\mathrm{Z}}$, with measurement by $\Delta I / I$ at $325 \mathrm{~nm}$ (Figure $7 \mathrm{~B}$ ).

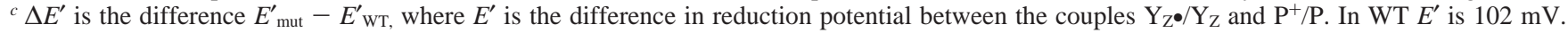

The Glu and Lys mutations lie at the two extremes, fastest and slowest, respectively, consistent with the expected charge and polarizability of these residues. The localization of a plus charge on $\mathrm{P}^{+}$would be most favored by the anionic Glu and least by Lys, a nonpolarizable neutral ligand.

A number of these mutants were further examined in vitro at $\mathrm{pH}$ 5.7. PSII core complexes lacking $\mathrm{Q}_{\mathrm{B}}$ and the manganese cluster were pretreated with concentrations of ferricyanide no more than several times that of the reaction centers $(\leq 1 \mu \mathrm{M})$, high enough to ensure the complete oxidation of $\mathrm{Q}_{\mathrm{A}}{ }^{-}$in the dark yet low enough so that electron transfer to ferricyanide does not compete with charge recombination. A single saturating light flash was given and the kinetics of reoxidation of $\mathrm{Q}_{\mathrm{A}}{ }^{-}$by charge recombination examined at $325 \mathrm{~nm}$ (Figure 7B, Table 3). On the basis of the kinetics of charge recombination in PSII core complexes at $\mathrm{pH} 5.7$ (Figure 7B, Table 3), we estimate the wild-type $K_{\text {zp }}=53$ (see also ref 81), corresponding to a difference in reduction potential between the redox couples $\mathrm{Y}_{\mathrm{Z}} / \mathrm{Y}_{\mathrm{Z}}$ and $\mathrm{P}^{+} / \mathrm{P}$ of $102 \pm 5 \mathrm{mV}$ at this $\mathrm{pH}$. A larger equilibrium constant $\left(K_{\text {zp }}=170\right)$ was estimated in PSII membranes from spinach by two of us (67), on the basis of on a value for $k_{\text {in }}=6000$ $\mathrm{s}^{-1}$ of Conjeaud and Mathis (82). The different estimates of $K_{\text {zp }}$ are likely due to species differences between spinach and Synechocystis and have little quantitative significance for the estimate of the $\Delta E^{\prime}$ of $\mathrm{P}$ between the mutants and WT. Mutants D1-His198Gln and D2-His197Asn show recombination rates practically indistinguishable from wild type in vitro. Mutants D1-His198Ala and Asn are markedly faster than wild type, in vitro as in vivo. The relative changes in $K_{\text {zp }}$ in Figure 7A,B were used to calculate (eqs 2 and 3) the displacement in millivolts of the reduction potential of $\mathrm{P}^{+} / \mathrm{P}$ shown in Table 3 .

The shifts in the donor side equilibria are also reflected in the forward rates of oxidation of $\mathrm{Y}_{\mathrm{Z}}$ by $\mathrm{P}^{+}$(kzp) as measured in PSII core complexes at $\mathrm{pH} 5.7$ (Figure 8). $\mathrm{P}^{+}$ reduction by $\mathrm{Y}_{\mathrm{Z}}$ was measured at $432 \mathrm{~nm}$, close to the bleaching minimum observed for $\mathrm{P}^{+}-\mathrm{P}(433 \mathrm{~nm}$; see Figure 8 ). The data in this figure have not been but the amplitude of $\mathrm{P}^{+}$reported in column 3 of Table 4 has been corrected

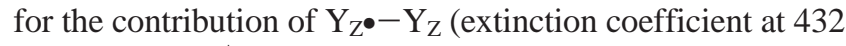
$\mathrm{nm} 11 \%$ of $\mathrm{P}^{+}-\mathrm{P}$ at $\left.433 \mathrm{~nm}\right)$ and $\mathrm{Q}_{\mathrm{A}}{ }^{-}-\mathrm{Q}_{\mathrm{A}}$ (extinction coefficient at $432 \mathrm{~nm} 1 \%$ of $\mathrm{P}^{+}-\mathrm{P}$ at $433 \mathrm{~nm}$ ) at this wavelength. These data were further corrected to account

\begin{tabular}{rcll}
\hline \multicolumn{4}{l}{ Table 4: Kinetics of $\mathrm{P}^{+}$Reduction by $\mathrm{Y}_{\mathrm{Z}}$} \\
\hline \multicolumn{5}{c}{ strain } & $\begin{array}{c}\text { \% slow } \mathrm{P}^{+} \text {redn } \\
\text { measd at } 0.2 \mathrm{~ms}^{b}\end{array}$ & $\begin{array}{c}\Delta E^{\prime}(\mathrm{mV}) \\
\left(\mathrm{P}^{+} / \mathrm{P}\right)^{c}\end{array}$ \\
\hline WT & 52 & 1.8 & -82 \\
D1-His198Ala & 32 & 31.7 & -43 \\
D1-His198Asn & 35 & 9.0 & slightly $\geq \mathrm{WT}$ \\
D1-His198Gln & 54 & slightly $\leq \mathrm{WT}$ & +27 \\
D2-His197Asn & 96 & 0.64 & -56 \\
D2-His197Gln & 29 & 14.2 & \\
\hline
\end{tabular}

${ }^{a} k_{1}$ is the rate constant for the fast phase of the biexponential fit. ${ }^{b}$ The reduction of $\mathrm{P}^{+}$was measured by $\Delta I / I$ at $432 \mathrm{~nm}$ (Figure 8). The amplitude of the slow phase of $\mathrm{P}^{+}$reduction was measured at $0.2 \mathrm{~ms}$ and corrected for the contributions of $\mathrm{Y}_{\mathrm{Z}} \bullet-\mathrm{Y}_{\mathrm{Z}}$ and $\mathrm{Q}_{\mathrm{A}}{ }^{-}-\mathrm{Q}_{\mathrm{A}} \cdot{ }^{c} \Delta E^{\prime}$ is the difference $E_{\text {mut }}^{\prime}-E_{\text {WT, }}^{\prime}$, where $E^{\prime}$ is the difference in reduction potential between the couples $\mathrm{Y}_{\mathrm{Z}} \bullet / \mathrm{Y}_{\mathrm{Z}}$ and $\mathrm{P}^{+} / \mathrm{P} . \Delta E^{\prime}$ was calculated from the data of column 3 . In WT, $E^{\prime}$ is $102 \mathrm{mV}$ from column 3 .

for the differences in the absorption maxima of the different mutants. Those mutants with the highest rates of charge recombination are also those with the lowest rates of $\mathrm{P}^{+}$ reduction, consistent with a slowing of $k_{\mathrm{zp}}$ upon a decrease of the driving force of the reaction (a lowering of the $E^{\prime}$ of redox couple $\mathrm{P}^{+} / \mathrm{P}$ ). With an increasingly negative $\Delta E^{\prime}$, the relaxation also becomes more markedly biphasic, reflecting the fact that the more negative the reduction potential of $\mathrm{P}^{+} / \mathrm{P}$ the closer it approaches that of $\mathrm{Y}_{\mathrm{Z}^{*}} / \mathrm{Y}_{\mathrm{Z}}$. An increasingly longlived component of $\mathrm{P}^{+}$is apparent which disappears by charge recombination or by reduction by ferrocyanide. Considering only the more rapid component of the biphasic fit ( $k_{1}$ in Table 4), the influence of the $\Delta E^{\prime}$ on the rate of forward electron transfer is rather weak, averaging a factor of +3.5 in rate per increase of $120 \mathrm{mV}$. Taking the amplitude of the slow phase $\left(A_{\mathrm{P}^{+}}\right.$, residual normalized concentration of $\mathrm{P}^{+}$at $0.2 \mathrm{~ms}$ ), we can estimate $K_{\text {zp }}$ (eq 4) which yields a difference in the reduction potentials of $\mathrm{Y}_{\mathrm{Z}^{\bullet}} / \mathrm{Y}_{\mathrm{Z}}$ and $\mathrm{P}^{+} / \mathrm{P}$ of $102 \pm 10 \mathrm{mV}$ in WT consistent with that calculated from charge recombination (above). We can also use $A_{\mathrm{P}^{+}}$to calculate $K_{\mathrm{zp}_{\text {mut }}}$ in the mutants and, using eqs 2 and 5 , the mutation-induced displacement of $E_{\mathrm{P}^{+} / \mathrm{P}}^{\prime}$ (Table 4).

$$
\begin{gathered}
K_{\mathrm{zp}}=\left[\left(1 / A_{\mathrm{P}+}\right)-1\right] \\
K_{\mathrm{zp}_{\mathrm{mut}}} / K_{\mathrm{zp}_{\mathrm{wt}}}=\left[\left(1 / A_{\mathrm{P}^{+}{ }_{\text {mut }}}\right)-1\right] /\left[\left(1 / A_{\mathrm{P}^{+}}{ }_{\mathrm{wt}}\right)-1\right]
\end{gathered}
$$

The $\Delta E^{\prime}$ values estimated from the slow phase of $\mathrm{P}^{+}$ reduction (Table 4) are consistent with the $\Delta E^{\prime}$ estimated 
from charge recombination (Table 3 ) in the same mutants. It was not possible to determine accurately in Figure 8 the amplitude of the slow phase for the D1-His198Gln mutant. The corrections for the difference in wavelength between the $\mathrm{P}^{+}-\mathrm{P}$ bleaching maximum and the contribution of $\mathrm{Y}_{\mathrm{Z}^{\bullet-}}$ $\mathrm{Y}_{\mathrm{Z}}$ are the largest in this mutant, and the amount of residual $\mathrm{P}^{+}$at $0.2 \mathrm{~ms}$ is quite small. However, the similarity in the kinetics of the fast phase of the $\mathrm{P}^{+}$relaxation for WT and the D1-His198GIn mutant (52 and $54 \mathrm{~s}^{-1}$, Table 4) indicates that the reduction potentials of $\mathrm{P}^{+} / \mathrm{P}$ are quite close.

\section{DISCUSSION}

Chlorophyll Coordination. Five coordinate ligation is thought to be the norm for the binding of chlorins in proteins and, on the basis of the neutral chlorophyll $\mathrm{C}=\mathrm{C}$ stretching modes (83), is likely true for $\mathrm{P}_{\mathrm{A}}$ and $\mathrm{P}_{\mathrm{B}}$ in PSII (27). The substitution of L-His173 and M-His200(202) with noncoordinating residues, either leucine or phenylalanine, in the reaction centers of $R b$. sphaeroides and $R b$. capsulatus results in the replacement of the Bchlorophyll with a Bpheophytin (36, 37). Substitution of the PSII homologues, D1-His198 and D2-His197, with leucine in Synechocystis 6803 results in the complete loss of the PSII reaction centers as detected by the absence of a variable fluorescence yield and of ${ }^{14} \mathrm{C}$ diuron binding (not shown). While at first sight this result implies that the presence of a coordinating residue is required for center assembly or stability, we show in this paper that noncoordinating residues such as alanine and even valine allow the centers to accumulate to levels that are 50-60\% and 5-10\%, respectively, of the wild type levels (Table 1). While these residues cannot themselves provide coordination, it is likely that the coordinating ligand in both cases is a water molecule, as in the case of porphyrins and chlorophylls in hydrocarbon solvents that have not been rendered anhydrous $(84,85)$. Steric exclusion of the water molecule by the amino acid residue side chain is the likely reason leucine and to a large extent valine block chlorophyll binding and consequently center assembly. The difference with the bacterial reaction centers may be that in PSII the axial coordination provided by the ligand contributes to a greater extent to the energetics of chromophore binding. Nonetheless, coordination of a Bchlorophyll by an axial ligand in $R b$. sphaeroides reaction centers is still the preferred binding motif over the replacement of the Bchlorophyll with Bpheophytin. Goldsmith et al. (39) and Schulz et al. (38) have shown that replacement of the coordinating His with Gly still results in Bchlorophyll binding but with water as the likely ligand. The same is likely true of the B-His656Gly mutation of PSI $(40,41)$. In PSII, PSI, and the bacterial reaction centers, the water ligand is likely hydrogen bonded directly or indirectly to the protein matrix. In the Ala and Gly mutants, water is the likely ligand, but the level of functional PS II centers is significantly different. Furthermore, the substitution of His by Gly works well in PS I and bacterial reaction centers but not in PS II ( $\leq 5 \%$ of WT). PSII may not tolerate well the increased flexibility inherent in the glycine replacement.

Reduction Potential of $P^{+} / P$. It has been proposed that one way in which the reduction potential of a chlorin might be elevated is through ring distortion $(27,86)$. This might be one way in which the potential of $\mathrm{P}^{+} / \mathrm{P}$ is raised above that of chlorophyll in organic solvents $(\sim+800 \mathrm{mV} ; 87)$.
FTIR spectroscopic evidence favors such a picture in PSII in that the chlorophyll or chlorophylls on which the $\mathrm{P}$ cation resides appear to have a distorted exocyclic ring (27), reducing the possibility of charge delocalization over the entire $\pi$ system of the molecule. Such distortion could diminish the binding energy of the chlorophyll association with the PSII reaction center, requiring either an axial ligand bound to the protein either covalently or a hydrogen bond to enhance the driving force for binding.

Ligand replacement, though more so on D1-His198 than on D2-His197, has substantial consequences for the redox and spectroscopic properties of $\mathrm{P}$ (Tables 3 and 4; Figures 7 and 8 ). This is in contrast with the bacterial reaction centers where the homologous glycine replacements are practically indistinguishable from wild type (39). The largest redox effects at D1-His198 are associated with His replacement by Glu and Ser. Both of these substantially stabilize the oxidizing equivalent on $\mathrm{P}$ as shown by the large acceleration of the rates of charge recombination between $\mathrm{Q}_{\mathrm{A}}{ }^{-}$and the donor side. As acceptor-donor side recombination occurs between $\mathrm{Q}_{\mathrm{A}}{ }^{-}$and $\mathrm{P}^{+}$, an enhanced concentration of the latter accelerates the recombination. This stabilization occurs at the expense of the localization of the oxidizing equivalent on $\mathrm{Y}_{\mathrm{Z}}$. The stabilization of the oxidizing equivalent on $\mathrm{P}^{+}$ is also reflected in the slowed electron transfer from $\mathrm{Y}_{\mathrm{Z}}$ to $\mathrm{P}^{+}$(Figure 8, Table 4), owing to the reduced driving force of the reaction. There is also a slow phase in the relaxation that increases as the reduction potential of the $\mathrm{P}^{+} / \mathrm{P}$ redox couple approaches that of $\mathrm{Y}_{\mathrm{Z}^{\bullet}} / \mathrm{Y}_{\mathrm{Z}}$. The slow phase corresponds to the concentration of $\mathrm{P}^{+}$in equilibrium with $\mathrm{Y}_{\mathrm{Z}}$. The enhanced stabilization of $\mathrm{P}^{+}$is understandable in the case of Glu where the axial ligand is anionic. In the case of Ala, the water molecule, which likely provides axial coordination, could either lose a proton through outright deprotonation to form $\mathrm{OH}^{-}$or through the displacement of a hydrogen bond to the protein. The latter mechanism may also apply in the cases of Ser and Cys. Replacement of D1His 198 with Lys on the other hand destabilizes the positive charge on $\mathrm{P}^{+}$as indicated by a slowing of charge recombination between $\mathrm{Q}_{\mathrm{A}}{ }^{-}$and the donor side. This ligand lacks the polarizability of the histidine to help stabilize the cation.

We pointed out in the Results section that the influence of $\Delta E^{\prime}$ on the rate of forward electron transfer is rather weak, averaging only a factor of +3.5 in rate per increase of 120 $\mathrm{mV}$ (Table 4). This weak dependence could mean that the reorganizational energy associated with $\mathrm{Y}_{\mathrm{Z}}$ to $\mathrm{P}^{+}$electron transfer is unusually low $(\leq 100 \mathrm{meV})$ with the rate versus free energy curve close to the Marcus inverted region (88). This possibility can, however, be excluded by the temperature studies of Renger et al. (89) that give a large reorganizational energy of $\sim 1.6 \mathrm{eV}$ for reduction of $\mathrm{P}^{+}$by $\mathrm{Y}_{\mathrm{Z}}$. More likely, the rate is limited by either a proton transfer $(68,81,90)$ or a protein conformational change and not by electron transfer.

Merry and co-workers (43) have used the percent formation of radical pair states at $60 \mathrm{ps}$ following an excitation pulse to calculate the free energy of charge separation relative to the singlet excited state of the reaction center $\left(\mathrm{RC}^{*}\right)$. These measurements were carried out in reaction centers isolated from Synechocystis wild type and from the D1-His198Gln and Ala mutants, the very same mutants studied here. These authors report at 60 ps a lowered radical pair yield for the D1-His198Gln mutant and a higher one for the D1- 
His198Ala mutant compared to WT. An increase in the reduction potential of $\mathrm{P}^{+} / \mathrm{P}$ is expected to raise to a similar extent the potential of the $\mathrm{P}^{+} / \mathrm{P}^{*}$ couple, decreasing the likelihood of charge separation relative to $\mathrm{RC}^{*}$. There is qualitative agreement between the present observations and those of Merry and co-workers (43). The latter authors propose that, compared to $\mathrm{WT}$, the $\mathrm{P}^{+} / \mathrm{P}$ couple is $13-19$ $\mathrm{mV}$ more positive for the D1-His198Gln mutant and 23$29 \mathrm{mV}$ more negative for the D1-His198Ala mutant. The signs of these changes are similar to what we observe in vivo ( +53 and $-74 \mathrm{mV}$, respectively), on the basis of the relative rates of charge recombination in whole cells but smaller in amplitude. Rates of $\mathrm{P}^{+}$reduction by $\mathrm{Q}_{\mathrm{A}}{ }^{-}$and $\mathrm{Y}_{\mathrm{Z}}$ measured spectroscopically in PSII core complexes show the $\mathrm{P}^{+} / \mathrm{P}$ redox couple of the D1-His $198 \mathrm{Gln}$ mutant to be nearly equipotential with wild type and that of the D1-His198Ala mutant again substantially more negative $(-84$ and $-82 \mathrm{mV}$, respectively). The differences between the in vivo and in vitro measurements may be a consequence of the loss of the Mn cluster which is known to influence the rate of reduction of $\mathrm{P}^{+}$by $\mathrm{Y}_{\mathrm{Z}}(82,91)$ and the difference in reduction potential between $\mathrm{Y}_{\mathrm{Z}^{\bullet}} / \mathrm{Y}_{\mathrm{Z}}$ and $\mathrm{P}^{+} / \mathrm{P}(92)$. The differences with the results of Merry et al. (43) may be due to their use of reaction center preparations as well as the early times at which their measurements are made (60 ps) as compared to our own which are on the seconds time scale. The slower measurements here allow ample time for protein-based relaxations to occur. Despite the quantitative differences, the qualitative similarities imply that the ability to stabilize $\mathrm{P}^{+}$has a direct influence on the quantum yield of charge separation.

The chemically understandable influence of the mutations on the reduction potential of $\mathrm{P}^{+} / \mathrm{P}$ and the comparison with the results of Merry et al. (43) argue that the mutations alter directly the reduction potential of the chlorophyll coordinated by the mutated ligand. This observation argues against the remaining interpretation (2a, mentioned in the Results section) of the mutation-induced displacement of the $\mathrm{P}^{+}-\mathrm{P}$ difference spectra-i.e., that a nearby oxidized chlorophyll produces an electrochromic shift in the spectrum of the chlorophyll bearing the mutated ligand.

Homologous substitutions on the D2-His197 coordinated chlorophyll give somewhat different results. Substitution of D1-His198 with Gln and Asn produce, respectively, none or even an increase in the reduction potential for the former and a decrease in reduction potential for the latter (Figures 7 and 8; Tables 3 and 4). At D2-His197, the effects of these two residues are smaller and reversed, with Gln showing the larger cation stabilization. These inverse effects likely stem from subtle differences in the coordination geometry of the two chlorophylls, possibly influencing the position of the $\mathrm{Mg}^{2+}$ with respect to the plane of the chlorin macrocycle. While substitution of His with Ala produces a stabilization of $\mathrm{P}^{+}$in both cases, the effect is also much smaller at D2His197 than it is at D1-His198 (Table 3).

Effects of Mutations on $P^{+}-P$ and $Y_{Z} \bullet-Y_{Z}$. All of the sitedirected mutations at D1-His198 examined with regard to $\mathrm{P}^{+}-\mathrm{P}$ show blue shifts in their difference spectra (Figures 1-3). This behavior is similar to the blue shift of the porphyrin Soret band when these molecules are dissolved in nonpolarizable (isopentane, ethyl ether) versus polarizable (e.g. pyridine, lutidine) solvents (85). A rapid electronic accommodation of the polarizable solvent to the reoriented dipole moment of the excited state produces a stabilization of the latter (red-shift). Here all of the ligands shown (Ala, Asn, and Gln) are less polarizable than His, resulting in a displacement to the blue of the ground-state absorbance spectrum and consequently of the bleaching minimum. A similar displacement of $2 \pm 0.5 \mathrm{~nm}$ is observed in PSI at 77 $\mathrm{K}$ for $\mathrm{P} 700^{+}-\mathrm{P} 700$ upon replacement by Gln, Ser, Asn, Cys, and Gly of A-His676 and B-His656, axial ligands to the special pair chlorophylls that constitute the primary electron donor of PSI $(40,41)$. Of the mutants discussed here, the largest shift is that of Gln. The $3 \mathrm{~nm}$ blue displacement observed in the Soret for D1-His198Gln from 433 to 430 $\mathrm{nm}$ is also observed for the Qy transition from 672.5 to 669.5 $\mathrm{nm}$ in the red (Figure 3). This spectral shift most likely reflects the spectral displacement of the $\mathrm{P}_{\mathrm{A}}$ chlorophyll absorbance spectrum. In support of this view, this chlorophyll, because of its proximity and orientation, is the major spectroscopic probe (see Results and Discussion below), responding in the Soret to the oxidation and reduction of $\mathrm{Y}_{\mathrm{Z}}$ and showing a $434 \mathrm{~nm}$ inflection and a 2-3 nm displacement of the $\mathrm{Y}_{\mathrm{Z}^{\bullet}}-\mathrm{Y}_{\mathrm{Z}}$ band shift by the D1-His198Gln mutation (Figure 4).

Observations in the red (Qy region) also show $\mathrm{P}_{\mathrm{A}}$ to be a probe for $\mathrm{Y}_{\mathrm{Z}}$ oxidation. The $\mathrm{P}^{+} \mathrm{Q}_{\mathrm{A}}{ }^{-}-\mathrm{PQ}_{\mathrm{A}}$ difference spectrum at $20 \mathrm{~K}$ in PSII-enriched membrane fragments from spinach and at $5 \mathrm{~K}$ in Synechococcus core complexes show a bleaching centered at 676 and $675 \mathrm{~nm}$, respectively (30, 54 ). These difference spectra are practically identical to those in Figure 3. Thus, these bleaching bands are the spinach and Synechococcus homologues of the D1-His198Gln sensitive $672.5 \mathrm{~nm}$ bleach in Synechocystis (Figure 3). Dekker (93) and Mulkidjanian et al. (65) have shown in PSII core complexes from spinach and pea, respectively, that $\mathrm{Y}_{\mathrm{Z}^{\bullet}-}$ $\mathrm{Y}_{\mathrm{Z}}$ displays a red band shift with an inflection at $677 \mathrm{~nm}$. Thus, as for the Soret band, the $\mathrm{Q}_{y}$ transition of the $\mathrm{P}_{\mathrm{A}}$ chlorophyll is the most sensitive probe of $\mathrm{Y}_{\mathrm{Z}}$ oxidation and is sensitive to the D1-His198Gln mutation. In summary then, the $\mathrm{P}_{\mathrm{A}}$ chlorophyll in Synechocystis has Soret and $\mathrm{Q}_{y}$ optical transitions centered at $433 \mathrm{~nm}$ (at $298 \mathrm{~K}$ ) and at $672.5 \mathrm{~nm}$ (at $80 \mathrm{~K}$ ), respectively.

Mulkidjanian et al. (65) have pointed out that of the two special pair, $\mathrm{P}_{\mathrm{A}}$ and $\mathrm{P}_{\mathrm{B}}$, chlorophylls with their $\mathrm{Q}_{y}$ transition moments aligned toward $\mathrm{Y}_{\mathrm{Z}}$ and $\mathrm{Y}_{\mathrm{D}}$, only the D2-His197 $\mathrm{P}_{\mathrm{B}}$ coordinated chlorophyll has the correct orientation to produce an electrochromic red-shift associated with $\mathrm{Y}_{\mathrm{Z}}$ oxidation. This conclusion is based on theoretical arguments of Fajer and collaborators (94) wherein placing a positive charge near pyrrole ring I produces a red electrochromic shift in the chlorophyll $\mathrm{Q}_{y}$ transition. Our ability to spectroscopically perturb the $\mathrm{P}_{\mathrm{A}}$ chlorophyll coordinated by D1-His198 leaves little doubt that the chlorophyll coordinated by this ligand is the spectroscopic probe for $\mathrm{Y}_{\mathrm{Z}^{\bullet}}-\mathrm{Y}_{\mathrm{Z}}$. Consequently, these observations call into question either the sign of the change in dipole moment between the ground and excited states of $\mathrm{P}_{\mathrm{A}}$ or the interpretation of the chlorophyll band shift, associated with $\mathrm{Y}_{\mathrm{Z}}$ oxidation, as being electrochromic in nature $(51,65,67)$. Preliminary experiments on the influence of $\mathrm{Y}_{\mathrm{D}} \bullet$ on the localization of the $\mathrm{P}^{+}$cation (see below) favor the retention of the phenolic proton upon $Y_{D}$ oxidation and an electrostatic effect on cation localization. These observations support the view that the $Y_{D^{\bullet}-} Y_{D}$ chlorophyll band shift is electrochromic in origin. From symmetry arguments 
and the similarity in shape of the $Y_{Z^{\bullet}}-Y_{Z}$ and the $Y_{D} \bullet-Y_{D}$ difference spectra (Figure 4), we believe that the $\mathrm{P}_{\mathrm{A}}$ band shift associated with $\mathrm{Y}_{\mathrm{Z}}$ oxidation is also electrochromic. We would then explain the red shift of the $\mathrm{P}_{\mathrm{A}}$ absorbance band upon $\mathrm{Y}_{\mathrm{Z}}$ oxidation in terms of a transition from the ground to the lowest excited singlet state of $\mathrm{P}_{\mathrm{A}}$ that results in a net movement of electron density from ring I to ring III rather than the other way around.

Stabilization of the $P^{+}$Cation on $P_{A}$. The bleaching observed in Figure 1A corresponds to an extinction coefficient of $4.1 \times 10^{4} \mathrm{M}^{-1} \mathrm{~cm}^{-1}$. The extinction coefficient of a chlorophyll molecule in the PSII core complex at $436\left(\lambda_{\max }\right)$ $\mathrm{nm}$ is approximately $7.4 \times 10^{4} \mathrm{M}^{-1} \mathrm{~cm}^{-1}$. While we do not know exactly what the contribution of $\mathrm{P}^{+}$alone is in the $\mathrm{P}^{+}-\mathrm{P}$ difference spectrum, the oscillator strength of this band is roughly consistent with what one would expect for the oxidation of a chlorophyll molecule. Likewise, Hillmann and co-workers $(30,54)$ have pointed out that the oscillator strength of the $80 \mathrm{~K}$ bleaching at $675-676 \mathrm{~nm}(672.5 \mathrm{~nm}$ in the present case, Figure 3) is also consistent with the oxidation of a chlorophyll molecule. In both the Soret and the $\mathrm{Q}_{y}$ cases, these bands are displaced to the blue to the same extent by the D1-His198Gln mutation. In the Soret region, all of the mutations introduced at D1-198 produce a displacement to the blue of $\mathrm{P}^{+}-\mathrm{P}$, consistent with the loss of the polarizable axial histidine ligand to the chlorophyll coordinated by D1-His198. The oscillator strength of the mutation-sensitive band, the blue shift for all D1-198 ligand replacements, and the observation in the Soret of the same blue displacement for $\mathrm{P}^{+}-\mathrm{P}$ as in the $\mathrm{Y}_{\mathrm{Z}} \bullet-\mathrm{Y}_{\mathrm{Z}}$ difference spectrum, the inflection point of which matches the bleaching maximum observed for $\mathrm{P}^{+}-\mathrm{P}$, all argue that it is the absorbance spectrum of $\mathrm{P}_{\mathrm{A}}$ that is displaced by the mutation. With regard to the last point, the FTIR difference spectrum

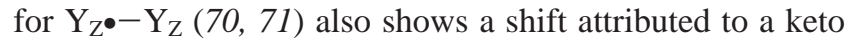
$\mathrm{C}_{9}=\mathrm{O}$ stretch at $1704-1707 \mathrm{~cm}^{-1}$ that is found in the $\mathrm{P}^{+}-\mathrm{P}$ difference spectrum $(27,95)$. These observations argue, therefore, against interpretation $2 \mathrm{~b}$ of the Results, whereby the D1-198 mutations modify the $\mathrm{P}^{+}-\mathrm{P}$ difference spectrum by a redistribution of the cationic charge. The site-directed mutations modify the reduction potential of the redox couple $\mathrm{P}^{+} / \mathrm{P}$ in a manner that is consistent with the ability of the axial ligand to stabilize or destabilize the $\mathrm{P}^{+}$cation on that chlorophyll (e.g. stabilization of the cation by glutamate, destabilization by lysine). Merry and co-workers (43) have shown that two of these same mutations (D1-His198Ala and Gln) increase and decrease, respectively, the extent of radical pair formation detected at $60 \mathrm{ps}$, consistent with the abovedescribed effects of coordination on the reduction potential of $\mathrm{P}^{+} / \mathrm{P}$. Both these observations and the dipole strength of the bleached band, displaced by the D1-198 mutations, argue that the $\mathrm{P}^{+}$cation resides on $\mathrm{P}_{\mathrm{A}}$ and not on an adjacent chlorophyll (e.g. $\mathrm{B}_{\mathrm{A}}$ ) that produces an electrochromic band shift of $\mathrm{P}_{\mathrm{A}}$ (possibility $2 \mathrm{a}$ described in the Results). In addition, $\mathrm{B}_{\mathrm{A}}$ is located over the center and near normal to the $\mathrm{P}_{\mathrm{A}}$ macrocycle and would be expected to produce little electrochromic shift even if it were to be the site of cation localization. We conclude therefore that the $\mathrm{P}^{+}$cation is primarily stabilized on $\mathrm{P}_{\mathrm{A}}$ at all temperatures on the basis of the observations at $5 \mathrm{~K} \mathrm{(30)}$ (see below), $80 \mathrm{~K}$ (Figure 3 ), and room temperature (Figures 1 and 2). An additional argument, based on $\mathrm{P}^{+}$-associated electrochromism in the bacterial reaction centers, is given below.

Location of ${ }^{3} \mathrm{P}$ as a Function of Temperature.

Both the ${ }^{3} \mathrm{P}-{ }^{1} \mathrm{P}$ and the $\mathrm{P}^{+}-\mathrm{P}$ difference spectra at $80 \mathrm{~K}$ show a bleaching in the red at $681 \mathrm{~nm}$ (Figures 3 and 5). Others have attributed the low-temperature bleaching at 681$686 \mathrm{~nm}$ to the oxidation of P680 $(27,30,54)$ and the band at $672-677 \mathrm{~nm}$ to either the low-yield oxidation of an accessory chlorophyll (27) or to an electrochromic band shift to the red accompanying $\mathrm{P}$ oxidation $(30,54)$. This latter attribution arises from the observation of a low-temperature bleaching at $684 \mathrm{~nm}$ for ${ }^{3} \mathrm{P} 680-{ }^{1} \mathrm{P} 680$ (30). Hillmann et al. $(30,54)$ proposed an explanation in which the positive charge and the triplet state were assumed to be located on the same chlorophyll with maximum absorption at $685 \mathrm{~nm}$ at low temperature.

On the basis of the current work, we prefer an alternative interpretation in which ${ }^{3} \mathrm{P}$ is stabilized on $\mathrm{B}_{\mathrm{A}}$ at $\leq 80 \mathrm{~K}$ and $\mathrm{P}^{+}$on $\mathrm{P}_{\mathrm{A}}$ at all temperatures. The arguments are as follows: (1) The chlorophyll on which the triplet is localized at $\leq 80$ $\mathrm{K}$ does not respond to the D1-His198Gln mutation as detected by optical difference or by EPR, implying that the triplet and the cation are not localized on the same chlorophyll. This observation is in agreement with FTIR studies $(27,95)$ that concluded, on the basis of the differences in the keto $\mathrm{C}_{9}=\mathrm{O}$ stretch frequencies, that at $\leq 80 \mathrm{~K}$ the chlorophyll on which the triplet is localized $\left(1669 \mathrm{~cm}^{-1}\right)$ and that (those) on which the cation is localized (1679 or 1704 $\mathrm{cm}^{-1}$ ) are different molecules. (2) The orientation studies $(24,62,74)$ on the low-temperature generated PSII reaction center triplet are consistent with the near membrane parallel orientation of the PSII homologues of $\mathrm{B}_{\mathrm{A}}$ and $\mathrm{B}_{\mathrm{B}}$ rather than the membrane perpendicular orientation of $\mathrm{P}_{\mathrm{A}}$ and $\mathrm{P}_{\mathrm{B}}(17$, 18). (3) In the bacterial reaction centers the electrochromic shift of the accessory chlorophyll $\left(\mathrm{B}_{\mathrm{A}}, \mathrm{B}_{\mathrm{B}}\right.$, or both) accompanying the oxidation of the primary donor is to the blue $(96,97)$. Because of the similar orientation of the reaction center chlorophylls to those of the bacterial reaction centers $(3,5,8,9,10,17,18,98)$, we expect a similar blue shift in PSII if the cation were localized on $\mathrm{P}_{\mathrm{A}}{ }^{+}$. If the cation were localized on $B_{A}$, then because of the closeness of ring I of $\mathrm{P}_{\mathrm{B}}$ to $\mathrm{B}_{\mathrm{A}}^{+}$, there would likely be an electrochromic shift of $\mathrm{P}_{\mathrm{B}}$ which would be insensitive to the D1-198 mutations. As mentioned above, the $\mathrm{B}_{\mathrm{A}}^{+}$cation would be located over the center and near normal to the $\mathrm{P}_{\mathrm{A}}$ macrocycle, producing little electrochromic shift. This geometry is inconsistent with an interpretation of the $\mathrm{P}_{\mathrm{A}}$ derived bleaching at $672.5 \mathrm{~nm}$ (Figure $3)$ as being part of an electrochromic red-shift $(30,54)$ induced by a positive charge on $\mathrm{B}_{\mathrm{A}}$. It is, however, consistent with the localization of the cation on $\mathrm{P}_{\mathrm{A}}$ accompanied by an electrochromic blue shift of $\mathrm{B}_{\mathrm{A}}$ as in the bacterial reaction centers (see below). We attribute, therefore, the principal bleaching at $672.5 \mathrm{~nm}$ to the formation of $\mathrm{P}_{\mathrm{A}}{ }^{+}$at $80 \mathrm{~K}$ and the absorbance increase at $678 \mathrm{~nm}$ and the bleaching at $682-$ $683 \mathrm{~nm}$ to a blue band shift of $\mathrm{B}_{\mathrm{A}}$ centered at $681-682$.

The ${ }^{3} \mathrm{P}-{ }^{1} \mathrm{P}$ difference spectra at 150 and $230 \mathrm{~K}$ (Figure 5B) are characterized by a shoulder at $669 \mathrm{~nm}$ that is present in the D1-His198Gln mutant but absent from the WT. These spectra, therefore, show evidence for a contribution from the blue-displaced $\mathrm{P}_{\mathrm{A}}$ absorbance band in the D1-His198Gln mutant, in contrast to those recorded at $\leq 80 \mathrm{~K}$, where the 

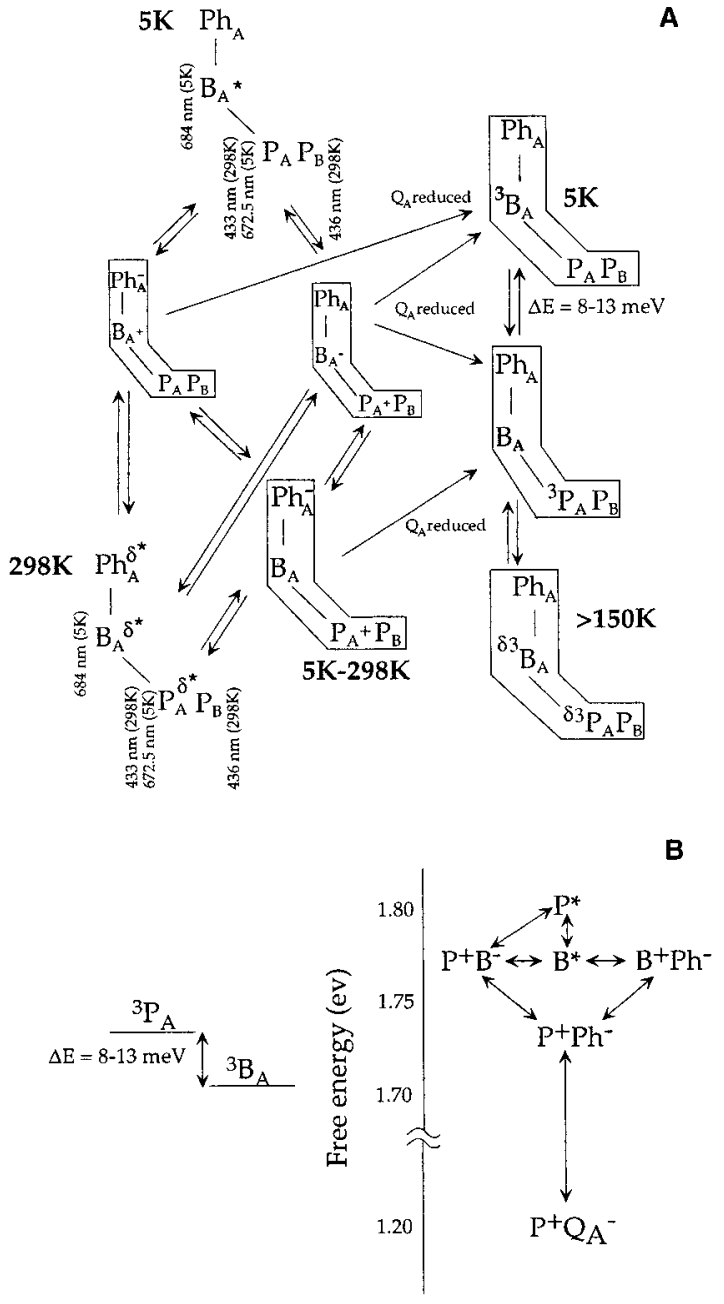

C

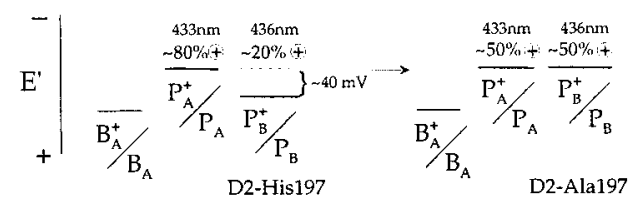

FIGURE 9: (A) Scheme indicating the various fates of the reaction center following center excitation at 5 and $298 \mathrm{~K}$. The initiators of primary charge separation are $\mathrm{B}_{\mathrm{A}} *$ at $5 \mathrm{~K}$ and $\mathrm{B}_{\mathrm{A}} *, \mathrm{P}_{\mathrm{A}} *$ and possibly $\mathrm{Ph}_{\mathrm{A}} *$ at $298 \mathrm{~K} .{ }^{3} \mathrm{P}$ is stabilized on $\mathrm{B}_{\mathrm{A}}$ at $5 \mathrm{~K}$ but is delocalized at $298 \mathrm{~K} . \mathrm{P}^{+}$is stabilized primarily on $\mathrm{P}_{\mathrm{A}}$ at all temperatures. Both the triplet and the cation are free to migrate to find the state of lowest free energy. (B) Energetics of excited and charge-separated states. The difference in free energy between the $B_{A}$ and $P_{A}$ chlorophyll triplet states assumes that the activation energy measured for the migration of the triplet $(27,62)$ reflects the difference in free energy between ${ }^{3} \mathrm{P}_{\mathrm{A}}$ and ${ }^{3} \mathrm{~B}_{\mathrm{A}}$. States $\mathrm{P}_{\mathrm{A}}{ }^{+} \mathrm{B}_{\mathrm{A}}{ }^{-}$and/ or $\mathrm{B}_{\mathrm{A}}{ }^{+} \mathrm{Ph}^{-}$are proposed to be approximately isoenergetic with $\mathrm{B}_{\mathrm{A}}{ }^{*}$ (see text). (C) Consequences of the directed mutation at D2-197 for the reduction potential of $\mathrm{P}_{\mathrm{B}}{ }^{+} / \mathrm{P}_{\mathrm{B}}$ and the partitioning of the cation between $\mathrm{P}_{\mathrm{A}}$ and $\mathrm{P}_{\mathrm{B}}$.

mutant and WT spectra show little difference. This observation is consistent with the triplet having migrated in an activated process to include the $\mathrm{P}_{\mathrm{A}}$ chlorophyll as the temperature is raised (Figure 9A). Noguchi et al. (63) have estimated the percent contribution of ${ }^{3} \mathrm{P}$ to the total reaction center triplet to be $\leq 30 \%$ at $20{ }^{\circ} \mathrm{C}$. This observation also further supports the EPR argument (see Results) that the triplet is generated and localized in the reaction center and not in the antenna complexes of CP47 and CP43. The exclusive detection of the reaction center triplet may have to do with rapid carotenoid quenching of the antenna but not of the reaction center triplets $(20)$. The temperature dependence observed here for the reaction center triplet localization is consistent with an 8-13 meV energy gap (27, $28,62,77)$ in which the triplet was proposed to be localized on an accessory chlorophyll at low temperature and mobile to include $\mathrm{P}$ as the temperature is raised (27). It is also consistent with a decrease in the zero field splitting parameters (narrowing of the triplet spectrum) with increasing temperature, indicative of a delocalization of triplet excitation with the same energy gap dependence (62). Preliminary studies indicated a change with temperature in the orientation of the zero field splitting tensor axes with the higher temperature component arising from a chlorophyll with its macrocycle perpendicular to the membrane plane (62). This observation is consistent with partial triplet localization onto $\mathrm{P}_{\mathrm{A}}$ at elevated temperature.

The localization of the reaction center triplet on $\mathrm{B}_{\mathrm{A}}$ at low temperature and on both $\mathrm{B}_{\mathrm{A}}$ and $\mathrm{P}_{\mathrm{A}}$ at elevated temperature can now be explained by the difference in the absorbance spectra of $\mathrm{P}_{\mathrm{A}}\left(\lambda_{\max }=672.5 \mathrm{~nm}\right.$ at both 5 and $80 \mathrm{~K}$, from Figure 3 and Hillmann et al. $(30,54)$; see below) and $\mathrm{B}_{\mathrm{A}}$ $\left(\lambda_{\max }=681 \mathrm{~nm}\right.$ at $80 \mathrm{~K}, 684 \mathrm{~nm}$ at $5 \mathrm{~K}$, Figure $\left.5 \mathrm{~A}\right)$. The long-wavelength assignment for $\mathrm{B}_{\mathrm{A}}$ is also consistent with low-temperature electrochromic band shifts observed upon reduction of $\mathrm{Q}_{\mathrm{A}}(64)$. As the ordering of the triplet state energies is parallel to that of the singlet states (99), it is clear that at low temperature the triplet excitation will reside on $\mathrm{B}_{\mathrm{A}}$, regardless of where the triplet were generated. As the temperature increases, $k T$ overcomes the $8-13 \mathrm{meV}$ gap in the triplet energies $(27,28,62)$ giving rise to triplet migration.

There is in ${ }^{3} \mathrm{P}-{ }^{1} \mathrm{P}$ difference spectra at 5 and $80 \mathrm{~K}$ of Figure 5A a small sideband observed between 665 and 672 $\mathrm{nm}$ that appears to be sensitive to the D1-His198GIn mutation, undergoing the same $\sim 3 \mathrm{~nm}$ displacement as observed in the $\mathrm{P}^{+}-\mathrm{P}$ difference spectra. This feature may be a reflection of the loss of weak exciton coupling $(\leq 100$ $\left.\mathrm{cm}^{-1}\right)(13,16)$ between $\mathrm{B}_{\mathrm{A}}$ and $\mathrm{P}_{\mathrm{A}}$ upon formation of ${ }^{3} \mathrm{~B}_{\mathrm{A}}$.

Charge Separation Is Initiated by $B_{A} *$. The difference in the absorbance spectra of $\mathrm{P}_{\mathrm{A}}$ and $\mathrm{B}_{\mathrm{A}}$ poses a fundamental question as to the location and mechanism of primary charge separation in PSII reaction centers. The similarity of the $\mathrm{P}^{+} \mathrm{Q}_{\mathrm{A}}{ }^{-}-\mathrm{PQ}_{\mathrm{A}}$ difference spectrum observed here at $80 \mathrm{~K}$ in Synechocystis to that observed at both $5 \mathrm{~K}(30)$ and $77 \mathrm{~K}$ (54) in Synechococcus indicates that the absorbance spectra of $\mathrm{P}_{\mathrm{A}}$ and $\mathrm{B}_{\mathrm{A}}$ are practically invariant between 5 and $80 \mathrm{~K}$ and that $\mathrm{P}^{+}$is stabilized on $\mathrm{P}_{\mathrm{A}}$ at all temperatures including at $5 \mathrm{~K}$. Given the difference in the energies of the lowest excited singlet states $(31 \mathrm{meV})$, the localization of singlet excitation on $\mathrm{B}_{\mathrm{A}}(684 \mathrm{~nm})$ over $\mathrm{P}_{\mathrm{A}}(672.5 \mathrm{~nm})$ is favored by a factor of $\sim 10^{31}$ at $5 \mathrm{~K}$. As the rate of charge separation is slower $(0.4-21 \mathrm{ps})(29,100-102)$ than the rate at which energy is equilibrated within the central pigments of the reaction center $(100-250 \mathrm{fs})(103,104)$, the excited state that drives charge separation must be on $\mathrm{B}_{\mathrm{A}}$ rather than on $\mathrm{P}_{\mathrm{A}}$ at low temperature (Figure 9A,B). This situation is different from what is observed in wild-type bacterial reaction centers where the strong coupling between the $\mathrm{P}_{\mathrm{A}}$ and $\mathrm{P}_{\mathrm{B}}$ 
homologues produces a low-energy exciton band that provides a trap for the excitation energy localized within the reaction center (for review see ref 97). Van Brederode et al. (105) have, however, shown that direct excitation of $\mathrm{B}_{\mathrm{A}}$ in reaction centers of $R b$. sphaeroides will produce $\mathrm{P}_{\mathrm{A}}^{+} \mathrm{B}_{\mathrm{A}}{ }^{-}$. Evidence for radical pair states generated directly from excitation of $\mathrm{B}_{\mathrm{A}}$ has also been obtained by Lin et al. (80) and Vos et al. (106). In bacterial reaction centers, isolated from the YM210W mutant in which charge separation from $\mathrm{P}^{*}$ is greatly slowed, $\mathrm{B}_{\mathrm{A}}{ }^{*}$ will produce $\mathrm{P}_{\mathrm{A}}{ }^{+} \mathrm{B}_{\mathrm{A}}{ }^{-}$and to a lesser extent $\mathrm{B}_{\mathrm{A}}{ }^{+} \mathrm{Pheo}^{-}$(107). $\mathrm{B}_{\mathrm{A}}{ }^{+} \mathrm{Pheo}^{-}$, however, is the dominant species produced from $\mathrm{B}_{\mathrm{A}} *$ in reaction centers containing the BChl:BPheo heterodimer (108). These authors have speculated that multiple routes for charge separation might exist as well in PSII owing to the much weaker exciton interaction between the reaction center pigments and the absence of a low-energy exciton band of $\mathrm{P}$ as a longwavelength trap $(33,35)$. With extrapolation from the bacterial reaction centers, these multiple routes have been proposed by Dekker and van Grondelle (33) as possible sources of the heterogeneity in the kinetics of charge separation that has been observed in PSII $(29,100-102)$. Because of the localization of the triplet and the oxidized donor on $\mathrm{P}$ in the bacterial reaction centers and the inclined orientation of the reaction center triplet in PSII, Rutherford and co-workers $(34,109)$ have speculated that the monomeric accessory $\mathrm{B}_{\mathrm{A}}$ chlorophyll might be all or part of P680.

As concluded here, the obligatory involvement of $\mathrm{B}_{\mathrm{A}} *$ in primary charge separation at low temperature points to the following pathways for primary charge separation in PSII under these conditions (Figure 9A,B):

$$
\mathrm{P}_{\mathrm{A}} \mathrm{B}_{\mathrm{A}}{ }^{*} \text { Pheo } \rightleftarrows \mathrm{P}_{\mathrm{A}}{ }^{+} \mathrm{B}_{\mathrm{A}}{ }^{-} \text {Pheo } \rightleftarrows \mathrm{P}_{\mathrm{A}}{ }^{+} \mathrm{B}_{\mathrm{A}} \mathrm{Pheo}^{-}
$$

and

$$
\mathrm{P}_{\mathrm{A}} \mathrm{B}_{\mathrm{A}}{ }^{*} \text { Pheo } \rightleftarrows \mathrm{P}_{\mathrm{A}} \mathrm{B}_{\mathrm{A}}{ }^{+} \mathrm{Pheo}^{-} \rightleftarrows \mathrm{P}_{\mathrm{A}}{ }^{+} \mathrm{B}_{\mathrm{A}} \mathrm{Pheo}^{-}
$$

One or the other or both of the $\mathrm{P}_{\mathrm{A}}{ }^{+} \mathrm{B}_{\mathrm{A}}{ }^{-} \mathrm{Pheo}$ and $\mathrm{P}_{\mathrm{A}} \mathrm{B}_{\mathrm{A}}{ }^{+} \mathrm{Pheo}^{-}$ states must be very close in energy to $\mathrm{B}_{\mathrm{A}}{ }^{*}$ for charge separation to occur at $5 \mathrm{~K}$. As the population of $\mathrm{P}_{\mathrm{A}} *$ increases with temperature, the more traditional

$$
\mathrm{P}_{\mathrm{A}} * \mathrm{~B}_{\mathrm{A}} \mathrm{Pheo} \rightleftarrows \mathrm{P}_{\mathrm{A}}{ }^{+} \mathrm{B}_{\mathrm{A}}{ }^{-} \text {Pheo } \rightleftarrows \mathrm{P}_{\mathrm{A}}{ }^{+} \mathrm{B}_{\mathrm{A}} \mathrm{Pheo}^{-}
$$

would be expected to increase. However, even at room temperature the location of the excited state on $\mathrm{B}_{\mathrm{A}}$ over $\mathrm{P}_{\mathrm{A}}$ would still be favored by a factor of 3.5. If, in addition, the rate of charge separation in PSII reaction centers from $\mathrm{B}_{\mathrm{A}}{ }^{*}$ is $\leq 1 \mathrm{ps}$, as in bacterial reaction centers (33), then the contribution of $\mathrm{B}_{\mathrm{A}} *$ to room-temperature charge separation may remain much greater than that from $\mathrm{P}_{\mathrm{A}} *$ for kinetic reasons as well. In core and larger complexes of PSII, the contribution of slow energy transfer steps ( $\geq 20 \mathrm{~ns})$ from the antenna to the reaction center is, however, likely to be rate limiting (33).

Peterman and collaborators (110) have examined at $5 \mathrm{~K}$ the vibronic fine structure of a line-narrowed PSII emission spectrum excited at $684-686.1 \mathrm{~nm}$. The emission spectrum shows a characteristic $\mathrm{C}_{9}=\mathrm{O}$ carbonyl stretch at $1669 \mathrm{~cm}^{-1}$, the same frequency observed by low-temperature FTIR in PSII reaction centers for the ${ }^{3} \mathrm{P}-{ }^{1} \mathrm{P}$ difference spectrum (27).
The excitation wavelength and the vibrational fine structure are both consistent with the excitation of $\mathrm{B}_{\mathrm{A}}$, the site of reaction center triplet localization at $\leq 80 \mathrm{~K}$. Konermann et al. (111) have also attributed to $\mathrm{B}_{\mathrm{A}}$ or $\mathrm{B}_{\mathrm{B}}$ of PSII the longest wavelength emission in PSII reaction centers. One interpretation of these observations (110) is that $\mathrm{B}_{\mathrm{A}} *$ shows a longlived singlet excited state because the charge separated states generated from $\mathrm{B}_{\mathrm{A}}{ }^{*}$ show a distribution around zero of free energy differences compared to $\mathrm{B}_{\mathrm{A}} *$. Some of these would require thermal activation and so would be inaccessible at 5 $\mathrm{K}$ leading to long-lived fluorescence. For this reason we place $\mathrm{P}^{+} \mathrm{B}_{\mathrm{A}}{ }^{-}$and/or $\mathrm{B}_{\mathrm{A}}{ }^{+} \mathrm{Pheo}^{-}$equipotential with $\mathrm{B}_{\mathrm{A}}{ }^{*}$ (Figure 9B). It would be of interest to examine these pathways further by examining the influence of the reduction potential of $\mathrm{P}^{+} / \mathrm{P}$ on the quantum yield of charge separation at low temperature as has been done at room temperature by Merry et al. (43).

We have not discussed the possible involvement of Pheo* in primary charge separation. While the active branch pheophytin is thought to absorb in the range of 679-683 $\mathrm{nm}(33,64)$, making it possible that Pheo* could contribute to charge separation as the temperature is raised, the results of Konermann et al. (112) and Peterman et al. (110) at 10 and $5 \mathrm{~K}$, respectively, show none or very little fluorescence emission from Pheo* $(\leq 10 \%)$, indicating that the singlet excitation is concentrated almost exclusively on $\mathrm{B}_{\mathrm{A}}{ }^{*}$ at these temperatures. At $77 \mathrm{~K}$, however, Pheo* becomes visible with a ratio of Chl* to Pheo* emission of 8:2 (112).

\section{Triplet and Cation Transfer.}

There has been no kinetically resolved triplet transfer observed in PSII. Thus either the triplet is generated at $\mathrm{B}_{\mathrm{A}}$ or it is generated elsewhere in 60-200 ns $(61-63)$ but is transferred to $\mathrm{B}_{\mathrm{A}}$ in a faster process. Both $\mathrm{P}_{\mathrm{A}}{ }^{+} \mathrm{B}_{\mathrm{A}}{ }^{-}$and $\mathrm{B}_{\mathrm{A}}{ }^{+} \mathrm{Pheo}^{-}$are possible intermediates that could result respectively in triplet formation through $\mathrm{HOMO}$ coupled or LUMO coupled electron transfer directly at $\mathrm{B}_{\mathrm{A}}$ without the need for triplet transfer. Noguchi et al. (63) have also proposed a concerted electron-transfer process involving $\mathrm{B}_{\mathrm{A}}$ and starting from $\mathrm{P}^{+} \mathrm{B}_{\mathrm{A}} \mathrm{Pheo}^{-}$. Likewise the cation could either be generated at $\mathrm{P}_{\mathrm{A}}$ directly $\left(\mathrm{B}_{\mathrm{A}}{ }^{*} \rightleftarrows \mathrm{P}_{\mathrm{A}}{ }^{+} \mathrm{B}_{\mathrm{A}}{ }^{-}\right.$and $\mathrm{P}_{\mathrm{A}}{ }^{*}$ $\rightleftarrows \mathrm{P}_{\mathrm{A}}^{+} \mathrm{B}_{\mathrm{A}}^{-}$) or migrate to $\mathrm{P}_{\mathrm{A}}$ from $\mathrm{B}_{\mathrm{A}}^{+}$following $\mathrm{B}_{\mathrm{A}}{ }^{*} \rightleftarrows$ $\mathrm{B}_{\mathrm{A}}{ }^{+} \mathrm{Pheo}^{-}$. This possibility has been previously proposed by Rutherford and co-workers $(32,109)$ and by Dekker and van Grondelle (33). From the results of Merry et al. (43) it is clear that mutations that affect the reduction potentials $\mathrm{P}_{\mathrm{A}}{ }^{+} /$ $\mathrm{P}_{\mathrm{A}}$ and the $\mathrm{Pheo}^{-} / \mathrm{Pheo}$ also have an impact on the yield of charge separation at $60 \mathrm{ps}$ following the excitation pulse. Thus radical pair states that include $\mathrm{P}_{\mathrm{A}}{ }^{+}$and $\mathrm{Pheo}^{-}$(mostly $\mathrm{P}_{\mathrm{A}}{ }^{+} \mathrm{Pheo}^{-}$) are already present at this time and are in equilibrium with the excited state of the reaction center. At the present state of knowledge, it is difficult to distinguish among these pathways, though picosecond spectroscopy involving selective excitation of $\mathrm{B}_{\mathrm{A}}$ and $\mathrm{P}_{\mathrm{A}}$ at low temperature could provide some discrimination among them. Mutations that alter component absorbance spectra, reduction potentials, and singlet excited-state lifetimes would be helpful as they have been in the bacterial reaction centers (e.g. ref 35).

Sharing of $P^{+}$Cation between $P_{A}$ and $P_{B}$. ENDOR measurements to examine the electronic structure of the oxidized primary electron donor in $R b$. sphaeroides reaction centers indicate that the $\mathrm{P}^{+}$cation is shared between the two special pair chlorophylls at a ratio of 2:1 (113). These authors 
showed that the ratio could be modified by site-directed mutations that affected the hydrogen-bonding characteristics of the special pair chlorophylls. There are in fact examples of bacterial reaction centers (e.g. Rb. capsulatus) where this ratio is more disequilibrated (5:1 (113)). Similar measurements in PSII $(114,115)$ have indicated a more asymmetric sharing of the $\mathrm{P}^{+}$cation between two or more chlorophylls with one chlorophyll dominating with a ratio estimated at 82:18 (114). Using FTIR, Breton and collaborators (116) observed in $R b$. sphaeroides reaction centers a mid-IR electronic band $\left(2600 \mathrm{~cm}^{-1}\right)$ arising from the charge delocalization of $\mathrm{P}^{+}$. Similar measurements in PSII (27; J. Breton personal communication) have identified a broad band centered at $1940 \mathrm{~cm}^{-1}$ in PSII that has been attributed to charge delocalization but more localized than in Rb. sphaeroides. The closeness of the maximum bleaching of the WT $\mathrm{P}^{+}-\mathrm{P}$ difference spectrum ( $433 \mathrm{~nm}$, Figure $2 \mathrm{~A}$ ) to the inflection point of the $Y_{Z^{\bullet}}-Y_{Z}$ difference spectrum $(443-434 \mathrm{~nm}$, Figure 4) as well as the larger changes in reduction potential and absorbance spectrum produced by D1-198 ligand replacement, as opposed to those at D2-197, are all consistent with preferential cation stabilization on $\mathrm{P}_{\mathrm{A}}$ over $\mathrm{P}_{\mathrm{B}}$.

Of the mutations constructed at D2-197, the most marked displacement of the maximum bleaching of the $\mathrm{P}^{+}-\mathrm{P}$ difference spectrum occurs in the D2-His197Ala mutation with a red-shift of $1-1.5 \mathrm{~nm}$ (Figure 2B). This shift is opposite in sign to what the same mutation produced at D1His198 (Figure 2A). This opposite displacement can be understood if we recall that the $Y_{D^{\bullet}}-Y_{D}$ difference spectrum shows an inflection point at $436 \mathrm{~nm}$. Considering the $C_{2}$ symmetry of the PSII reaction center, it is likely that the major spectroscopic probe for $Y_{D} \bullet-Y_{D}$ is the $P_{B}$ chlorophyll coordinated by D2-His197, just as $\mathrm{P}_{\mathrm{A}}$ is the major probe for $\mathrm{Y}_{\mathrm{Z}} \bullet-\mathrm{Y}_{\mathrm{Z}}$. Thus, it is likely that the ground-state absorption spectrum of this chlorophyll shows a peak at $436 \mathrm{~nm}$, different from the 433 peak shown by the D1-His 198 coordinated $\mathrm{P}_{\mathrm{A}}$ chlorophyll. The charge recombination experiment performed in whole cells of the D2-His197Ala mutant shows this mutation to induce a small stabilization of $\mathrm{P}^{+}$(Table 3). It is likely, therefore, that the cation is shared between $\mathrm{P}_{\mathrm{A}}$ and $\mathrm{P}_{\mathrm{B}}$, with the former the more dominant of the two in WT. Upon introduction of the D2-His197Ala mutation, the chlorophyll coordinated by the D2-197 ligand is stabilized to cation localization (Figure 9C). The displacement to the red of the $\mathrm{P}^{+}-\mathrm{P}$ bleaching minimum is then understandable as the $436 \mathrm{~nm} \mathrm{P}_{\mathrm{B}}$ chlorophyll makes an increased contribution to the $\mathrm{P}^{+}-\mathrm{P}$ difference spectrum at the expense of the $\mathrm{P}_{\mathrm{A}}$ chlorophyll absorbing at $433 \mathrm{~nm}$. To explain these differences, we propose a model in which the reduction potentials of $\mathrm{P}_{\mathrm{A}}$ and $\mathrm{P}_{\mathrm{B}}$ differ by approximately $40 \mathrm{mV}$ to account for the $80: 20$ distribution of the oxidizing equivalent (114), with the D2-His 197 coordinated $\mathrm{P}_{\mathrm{B}}$ chlorophyll the more positive of the two. Upon introduction of the Ala replacement at this site, the reduction potential of this chlorophyll decreases by $20-40 \mathrm{mV}$ such that the two chlorophylls are more nearly equipotential. This model of the two chlorophylls is depicted in Figure 9C. However, were the D2-His197Ala mutation to induce a displacement to the blue of the ground-state absorption band of $\mathrm{P}_{\mathrm{B}}$ (not examined), then the mutation-induced decrease in reduction potential of this chlorophyll would be larger still.
That there are differences in the absorbance spectra for the D1-His198 and the D2-His197 coordinated chlorophylls implies that the exciton coupling between them is quite weak $\left(85-140 \mathrm{~cm}^{-1}(13-16,23)\right)$ in contrast to what is observed for the special pair Bchlorophylls of the bacterial reaction centers $\left(500-1000 \mathrm{~cm}^{-1}(1,2)\right)$. This observation is consistent with the estimated $10 \AA$ center to center distance between the metal centers of these chlorophylls from electron and X-ray diffraction studies of PSII crystals $(17,18,73)$ as opposed to the $7.6 \AA$ found in bacterial reaction centers (35).

We have preferred to use the terminology $\mathrm{P}$ rather than P680 for the chlorophyll(s) on which the cation is stabilized to avoid implying that there is a single species, the absorbance maximum of which is located at $680 \mathrm{~nm}$ at room temperature. It is likely that both $\mathrm{P}_{\mathrm{A}}$ and $\mathrm{B}_{\mathrm{A}}$ and to some extent $\mathrm{P}_{\mathrm{B}}$ all contribute to the room-temperature $\mathrm{P}^{+}-\mathrm{P}$ difference spectrum, the first and the third because they bear the cation and the second because of its electrochromic contribution.

We have shown here that the exchange of axial ligands of individual chlorophyll molecules in PSII reaction centers can provide spectroscopic markers for those chlorophylls as well as providing a means to tune their redox properties. These features have allowed us to identify those chlorophylls on which the $\mathrm{P}^{+}$cation and reaction center triplet are localized as well as those that detect, by their band shifts, the oxidation of the redox active tyrosines, $\mathrm{Y}_{\mathrm{Z}}$ and $\mathrm{Y}_{\mathrm{D}}$. Particularly striking is the conclusion that at low temperature primary charge separation is driven exclusively by the excited state of the monomeric accessory chlorophyll, $\mathrm{B}_{\mathrm{A}}$. This species is likely to be a major participant in charge separation even at ambient temperatures. The kind of axial ligand replacement that we have carried out here could also be used to probe for the sites of coordination of $\mathrm{B}_{\mathrm{A}}$ and $\mathrm{B}_{\mathrm{B}}$. Changes in their spectroscopic and redox properties are likely to have important consequences for the energetics and kinetics of primary charge separation that should contribute to a better understanding of this process in PSII.

\section{ACKNOWLEDGMENT}

B.A.D. gratefully acknowledges valuable discussions with Drs. Gary Brudvig, Jack Fajer, Harry Frank, David Mauzerall, A. William Rutherford, Hans van Gorkom, and Rienk van Grondelle. We thank Mary Jane Gladnick Reeve, Jamie Yehong Wang, Marianne Çetin, Cathy Madsen, and Michael Lince for excellent technical assistance.

\section{REFERENCES}

1. Knapp, E. W., Fischer, S. F., Zinth, W., Sander, M., Kaiser, W., Deisenhofer, J., and Michel, H. (1985) Proc. Natl. Acad. Sci. U.S.A. 82, 8463-7.

2. Zinth, W., Knapp, E. W., Fischer, S. F., Kaiser, W., Deisenhofer, J., and Michel, H. (1985) Chem. Phys. Lett. 119, 1-4.

3. Michel, H., Epp, O., and Deisenhofer, J. (1986) EMBO J. 5, 2445-51.

4. Allen, J. P., Feher, G., Yeates, T. O., Rees, D. C., Deisenhofer, J., Michel, H., and Huber, R. (1986) Proc. Natl. Acad. Sci. U.S.A. 83, 8589-93.

5. El-Kabbani, O., Chang, C. H., Tiede, D., Norris, J., and Schiffer, M. (1991) Biochemistry 30, 5361-9. 
6. Lendzian, F., Huber, M., Isaacson, R. A., Endeward, B., Plato, M., Boenigk, B., Moebius, K., Lubitz, W., and Feher, G. (1993) Biochim. Biophys. Acta 1183, 139-60.

7. Trebst, A. (1986) Z. Naturforsch., C: Biosci. 41, 240-5.

8. Michel, H., and Deisenhofer, J. (1988) Biochemistry 27, 1-7.

9. Ruffle, S. V., Donnelly, D., Blundell, T. L., and Nugent, J. H. A. (1992) Photosynth. Res. 34, 287-300.

10. Svensson, B., Etchebest, C., Tuffery, P., Kan, P. v., Smith, J., and Styring, S. (1996) Biochemistry 35, 14486-14502.

11. Klimov, V. V., and Krasnovskii, A. A. (1981) Photosynthetica 15, 592-609.

12. Diner, B. A., and Babcock, G. T. (1996) in Oxygenic Photosynthesis: The Light Reactions (Ort, D. R., and Yocum, C. F., Eds.) pp 213-247, Kluwer Academic Publishers, Dordrecht, The Netherlands.

13. Tetenkin, V. L., Gulyaev, B. A., Seibert, M., and Rubin, A. B. (1989) FEBS Lett. 250, 459-63.

14. Braun, P., Greenberg, B. M., and Scherz, A. (1990) Biochemistry 29, 10376-87.

15. Kwa, S. L. S., Eijckelhoff, C., van Grondelle, R., and Dekker, J. P. (1994) J. Phys. Chem. 98, 7702-11.

16. Durrant, J. R., Klug, D. R., Kwa, S. L. S., van Grondelle, R., Porter, G., and Dekker, J. P. (1995) Proc. Natl. Acad. Sci. U.S.A. 92, 4798-802.

17. Rhee, K. H., Morris, E. P., Barber, J., and Kuhlbrandt, W. (1998) Nature 396, 283-6.

18. Zouni, A., Witt, H.-T., Kern, J., Fromme, P., Krauss, N., Saenger, W., and Orth, P. (2001) Nature (London) 409, 739743.

19. Rutherford, A. W., Paterson, D. R., and Mullet, J. E. (1981) Biochim. Biophys. Acta 635, 205-14.

20. Takahashi, Y., Hansson, O., Mathis, P., and Satoh, K. (1987) Biochim. Biophys. Acta 893, 49-59.

21. Den Blanken, H. J., Hoff, A. J., Jongenelis, A. P. J. M., and Diner, B. A. (1983) FEBS Lett. 157, 21-7.

22. Durrant, J. R., Giorgi, L. B., Barber, J., Klug, D. R., and Porter, G. (1990) Biochim. Biophys. Acta 1017, 167-75.

23. van Kan, P. J. M., Otte, S. C. M., Kleinherenbrink, F. A. M., Nieveen, M. C., Aartsma, T. J., and van Gorkom, H. J. (1990) Biochim. Biophys. Acta 1020, 146-52.

24. van Mieghem, F. J. E., Satoh, K., and Rutherford, A. W. (1991) Biochim. Biophys. Acta 1058, 379-85.

25. Tiede, D. M., and Dutton, P. L. (1981) Biochim. Biophys. Acta 637, 278-90.

26. Hales, B. J., and Das Gupta, A. (1979) Biochim. Biophys. Acta $548,276-86$.

27. Noguchi, T., Tomo, T., and Inoue, Y. (1998) Biochemistry 37, 13614-13625.

28. Noguchi, T., Inoue, Y., and Satoh, K. (1993) Biochemistry 32, 7186-95.

29. Schelvis, J. P. M., Noort, P. I. v., Aartsma, T. J., and van Gorkom, H. J. (1994) Biochim. Biophys. Acta 1184, 242-50.

30. Hillmann, B., Brettel, K., van Mieghem, F., Kamlowski, A., Rutherford, A. W., and Schlodder, E. (1995) Biochemistry 34, 4814-27.

31. van Mieghem, F. (1994) Thesis, University of Wageningen.

32. van Mieghem, F. J. E., and Rutherford, A. W. (1993) Biochem. Soc. Trans. 21, 986-91.

33. Dekker, J. P., and van Grondelle, R. (2000) Photosynth. Res. 63, 195-208.

34. Rutherford, A. W. (1988) in Light Energy Transduction in Photosynthesis: Higher Plant and Bcterial Models (Stevens, S. E., and Bryant, D. A., Eds.) pp 163-177, The American Society of Plant Physiologists, Rockville, MD.

35. Brederode, M. E. v., and Grondelle, R. v. (1999) FEBS Lett. $455,1-7$.

36. Bylina, E. J., and Youvan, D. C. (1988) Proc. Natl. Acad. Sci. U.S.A. 85, 7226-30.

37. Schenck, C. C., Gaul, D., Steffen, M., Boxer, S. G., McDowell, L., Kirmaier, C., and Holten, D. (1990) in Reaction Centers of Photosynthetic Bacteria: Feldefing II Meeting (MichelByerle, M.-E., Ed.) pp 229-238, Springer-Verlag, Berlin.

38. Schulz, C., Muh, F., Beyer, A., Jordan, R., Schlodder, E., and Lubitz, W. (1998) in Photosynthesis: Mechanism and Effects
(Garab, G., Ed.) pp 767-770, Kluwer Academic Publishers, Dordrecht, The Netherlands.

39. Goldsmith, J. O., King, B., and Boxer, S. G. (1996) Biochemistry 35, 2421-8.

40. Webber, A. N., Su, H., Bingham, S. E., Kaess, H., Krabben, L., Kuhn, M., Jordan, R., Schlodder, E., and Lubitz, W. (1996) Biochemistry 35, 12857-12863.

41. Krabben, L., Schlodder, E., Jordan, R., Carbonera, D., Giacometti, G., Lee, H., Webber, A. N., and Lubitz, W. (2000) Biochemistry 39, 13012-13025.

42. Coleman, W. J., Nixon, P. J., Vermaas, W. F. J., and Diner, B. A. (1995) in Photosynthesis: from Light to Biosphere (Mathis, P., Ed.) pp 779-782, Kluwer Academic Publishers, Dordrecht, The Netherlands.

43. Merry, S. A. P., Nixon, P. J., Barter, L. M. C., Schilstra, M., Porter, G., Barber, J., Durrant, J. R., and Klug, D. R. (1998) Biochemistry 37, 17439-17447.

44. Nixon, P. J., Trost, J. T., and Diner, B. A. (1992) Biochemistry $31,10859-71$.

45. Tang, X. S., Chisholm, D. A., Dismukes, G. C., Brudvig, G. W., and Diner, B. A. (1993) Biochemistry 32, 13742-8.

46. Vermaas, W., Charité, J., and Eggers, B. (1990) in Current Research in Photosynthesis (Baltscheffsky, M., Ed.) pp 2318, Kluwer Academic Publishers, Dordrecht, The Netherlands.

47. Rögner, M., Nixon, P. J., and Diner, B. A. (1990) J. Biol. Chem. 265, 6189-96.

48. Tang, X.-S., and Diner, B. A. (1994) Biochemistry 33, 4594603.

49. Diner, B. A., and de Vitry, C. (1984) in Advances in Photosynthesis Research (Sybesma, C., Ed.) pp 407-11, Martinus Nijhoff/Dr. W. Junk, The Hague.

50. Metz, J. G., Nixon, P. J., Rögner, M., Brudvig, G. W., and Diner, B. A. (1989) Biochemistry 28, 6960-9.

51. Diner, B. A., Tang, X.-S., Zheng, M., Dismukes, G. C., Force, D. A., Randall, D. W., and Britt, R. D. (1995) in Photosynthesis: from Light to Biosphere (Mathis, P., Ed.) pp 229234, Kluwer Academic Publishers, Dordrecht, The Netherlands.

52. Joliot, P., Béal, D., and Frilley, B. (1980) J. Chim. Phys. 77, 209-16.

53. Diner, B. A. (1998) Methods Enzymol. 297, 337-360.

54. Hillmann, B., and Schlodder, E. (1995) Biochim. Biophys. Acta 1231, 76-88.

55. Béal, D., Rappaport, F., and Joliot, P. (1999) Rev. Sci. Instrum. 70, 202-207.

56. van Mieghem, F. J. E., Nitschke, W., Mathis, P., and Rutherford, A. W. (1989) Biochim. Biophys. Acta 977, 20714.

57. Eskins, K., Scholfield, C. R., and Dutton, H. J. (1977) J. Chromatogr. 135, 217-20.

58. Vermaas, W., Charite, J., and Shen, G. (1990) Z. Naturforsch., C: Biosci. 45, 359-65.

59. Nixon, P. J., Chisholm, D. A., and Diner, B. A. (1992) in Plant Protein Engineering (Shewry, P. R., and Gutteridge, S., Eds.) pp 93-141, Cambridge University Press, Cambridge, U.K.

60. Vermaas, W. F. J., Ikeuchi, M., and Inoue, Y. (1988) Photosynth. Res. 17, 97-113.

61. Volk, M., Gilbert, M., Rousseau, G., Richter, M., Ogrodnik, A., and Michel-Beyerle, M.-E. (1993) FEBS Lett. 336, 35762.

62. Kamlowski, A., Frankemöller, L., van der Est, A., Stehlik, D., and Holzwarth, A. (1996) Ber. Bunsen-Ges. Phys. Chem. 100, 2045-2051.

63. Noguchi, T., Tomo, T., and Kato, C. (2001) Biochemistry 40, 2176-2185.

64. Stewart, D. H., Nixon, P. J., Diner, B. A., and Brudvig, G. W. (2000) Biochemistry 39, 14583-14594.

65. Mulkidjanian, A. Y., Cherepanov, D. A., Haumann, M., and Junge, W. (1996) Biochemistry 35, 3093-107.

66. Dekker, J. P., Van Gorkom, H. J., Brok, M., and Ouwehand, L. (1984) Biochim. Biophys. Acta 764, 301-9.

67. Rappaport, F., and Lavergne, J. (1997) Biochemistry 36, 15294-15302. 
68. Ahlbrink, R., Haumann, M., Cherepanov, D., Boegershausen, O., Mulkidjanian, A., and Junge, W. (1998) Biochemistry 37, 1131-1142.

69. Tommos, C., McCracken, J., Styring, S., and Babcock, G. T. (1998) J. Am. Chem. Soc. 120, 10441-10452.

70. Zhang, H., Razeghifard, M. R., Fischer, G., and Wydrzynski, T. (1997) Biochemistry 36, 11762-11768.

71. Berthomieu, C., Hienerwadel, R., Boussac, A., Breton, J., and Diner, B. A. (1998) Biochemistry 37, 10547-10554.

72. Hienerwadel, R., Boussac, A., Breton, J., Diner, B., and Berthomieu, C. (1997) Biochemistry 36, 14712-14723.

73. Barber, J., and Kuhlbrandt, W. (1999) Curr. Opin. Struct. Biol. 9, 469-475.

74. van der Vos, R., van Leeuwen, P. J., Braun, P., and Hoff, A. J. (1992) Biochim. Biophys. Acta 1140, 184-98.

75. Frank, H. A., Friesner, R., Nairn, J. A., Dismukes, G. C., and Sauer, K. (1979) Biochim. Biophys. Acta 547, 484-501.

76. Frank, H. A., Bolt, J., Friesner, R., and Sauer, K. (1979) Biochim. Biophys. Acta 547, 502-11.

77. Bosch, M. K., Proskuryakov, I. I., Gast, P., and Hoff, A. J. (1996) J. Phys. Chem. 100, 2384-90.

78. Budil, D. E., and Thurnauer, M. C. (1991) Biochim. Biophys. Acta 1057, 1-41.

79. Kok, B., Forbush, B., and McGloin, M. (1970) Photochem. Photobiol. 11, 457-75.

80. Lin, X., Murchison, H. A., Nagarajan, V., Parson, W. W., Allen, J. P., and Williams, J. C. (1994) Proc. Natl. Acad. Sci. U.S.A. 91, 10265-9.

81. Diner, B. A., Force, D. A., Randall, D. W., and Britt, R. D. (1998) Biochemistry 37, 17931-17943.

82. Conjeaud, H., and Mathis, P. (1980) Biochim. Biophys. Acta 590, 353-9.

83. Fujiwara, M., and Tasumi, M. (1986) J. Phys. Chem. 90, 2505.

84. Cotton, T. M., Loach, P. A., Katz, J. J., and Ballschmiter, K. (1978) Photochem. Photobiol. 27, 735-49.

85. Belanger, F. C., and Rebeiz, C. A. (1984) Spectrochim. Acta, Part A 40A, 807-27.

86. Barkigia, K. M., and Fajer, J. (1993) in The Photosynthetic Reaction Center (Deisenhofer, J., and Norris, J. R., Eds.) pp 513-39, Academic Press, San Diego, CA.

87. Watanabe, T., and Kobayashi, M. (1991) in The Chlorophylls (Scheer, H., Ed.) pp 287-315, CRC Press, Boca Raton, FL.

88. Moser, C. C., Keske, J. M., Warncke, K., Farid, R. S., and Dutton, P. L. (1993) in The Photosynthetic Reaction Center (Deisenhofer, J., and Norris, J. R., Eds.) pp 1-22, Academic Press, San Diego, CA.

89. Renger, G., Christen, G., Karge, M., Eckert, H. J., and Irrgang, K. D. (1998) J. Biol. Inorg. Chem. 3, 360-366.

90. Hays, A. M., Vassiliev, I. R., Golbeck, J. H., and Debus, R. J. (1998) Biochemistry 37, 11352-65.

91. Brettel, K., Schlodder, E., and Witt, H. T. (1984) Biochim. Biophys. Acta 766, 403-15.

92. Yerkes, C. T., Babcock, G. T., and Crofts, A. R. (1983) FEBS Lett. 158, 359-63.

93. Dekker, J. P. (1985) Thesis, University of Leiden.

94. Fajer, J., Hanson, L. K., Zerner, M. C., and Thompson, M. A. (1992) NATO ASI Ser., Ser. A 237, 33-42.

95. Sarcina, M., Breton, J., Nabedryk, E., Diner, B. A., and Nixon, P. J. (1998) in Photosynthesis: Mechanisms and Effects (Garab, G., Ed.) pp 1053-1056, Kluwer Academic Publishers, Dordrecht, The Netherlands.
96. Hanson, L. K., Fajer, J., Thompson, M. A., and Zerner, M. C. (1987) J. Am. Chem. Soc. 109, 4728-30.

97. Woodbury, N. W., and Allen, J. P. (1995) in Anoxygenic Photosynthesis (Blankenship, R. E., Madigan, M. T., and Bauer, C. E., Eds.) pp 527-557, Kluwer Academic Publishers, Dordrecht, The Netherlands.

98. Yeates, T. O., Komiya, H., Chirino, A., Rees, D. C., Allen, J. P., and Feher, G. (1988) Proc. Natl. Acad. Sci. U.S.A. 85, 7993-7.

99. McGlynn, S. P., Azumi, T., and Kinoshita, M. (1969) Molecular Spectroscopy of the Triplet State Prentice Hall, Englewood Cliffs, NJ.

100. Wasielewski, M. R., Johnson, D. G., Seibert, M., and Govindjee. (1989) Proc. Natl. Acad. Sci. U.S.A. 86, 524-8.

101. Klug, D. R., Rech, T., Joseph, D. M., Barber, J., Durrant, J. R., and Porter, G. (1995) Chem. Phys. 194, 433-42.

102. Groot, M.-L., van Mourik, F., Eijckelhoff, C., van Stokkum, I. H. M., Dekker, J. P., and van Grondelle, R. (1997) Proc. Natl. Acad. Sci. U.S.A. 94, 4389-4394.

103. Durrant, J. R., Hastings, G., Joseph, D. M., Barber, J., Porter, G., and Klug, D. R. (1992) Proc. Natl. Acad. Sci. U.S.A. 89, 11632-6.

104. Mueller, M. G., Hucke, M., Reus, M., and Holzwarth, A. R. (1996) J. Phys. Chem. 100, 9527-9536.

105. Van Brederode, M. E., Van Mourik, F., Van Stokkum, I. H. M., Jones, M. R., and Van Grondelle, R. (1999) Proc. Natl. Acad. Sci. U.S.A. 96, 2054-2059.

106. Vos, M. H., Breton, J., and Martin, J.-L. (1997) J. Phys. Chem. B 101, 9820-9832.

107. Van Brederode, M. E., Jones, M. R., Van Mourik, F., Van Stokkum, I. H. M., and Van Grondelle, R. (1997) Biochemistry $36,6855-6861$

108. van Brederode, M. E., van Stokkum, I. H. M., Katilius, E., van Mourik, F., Jones, M. R., and van Grondelle, R. (1999) Biochemistry 38, 7545-7555.

109. Rutherford, A. W., and Nitschke, W. (1996) in Origin and Evolution of Biological Energy Conversion (Baltscheffsky, H., Ed.) pp 143-175, VCH, New York.

110. Peterman, E. J. G., Van Amerongen, H., Van Grondelle, R., and Dekker, J. P. (1998) Proc. Natl. Acad. Sci. U.S.A. 95, 6128-6133.

111. Konermann, L., and Holzwarth, A. R. (1996) Biochemistry $35,829-42$.

112. Konermann, L., Yruela, I., and Holzwarth, A. R. (1997) Biochemistry 36, 7498-7502.

113. Rautter, J., Lendzian, F., Lubitz, W., Wang, S., and Allen, J. P. (1994) Biochemistry 33, 12077-84.

114. Rigby, S. E. J., Nugent, J. H. A., and O’Malley, P. J. (1994) Biochemistry 33, 10043-50.

115. Telfer, A., Lendzian, F., Schlodder, E., Barber, J., and Lubitz, W. (1998) in Photosynthesis: Mechanism and Effects (Garab, G., Ed.) pp 1061-1064, Kluwer Academic Publishers, Dordrecht, The Netherlands.

116. Breton, J., Nabedryk, E., and Parson, W. W. (1992) Biochemistry 31, 7503-10.

117. Rippka, R., Deruelles, J., Waterbury, J. B., Herdman, M., and Stanier, R. Y. (1979) J. Gen. Microbiol. 111, 1-61.

BI010121R 